\title{
Glyphosate's impact on vegetative growth in leafy spurge identifies molecular processes and hormone cross-talk associated with increased branching
}

Münevver Doğramacı ${ }^{1}$, Michael E. Foley ${ }^{1}$, David P. Horvath'1 , Alvaro G. Hernandez², Radhika S. Khetani², Christopher J. Fields' ${ }^{2}$ Kathleen M. Keating ${ }^{2}$, Mark A. Mikel ${ }^{3}$ and James V. Anderson ${ }^{1 *}$

\begin{abstract}
Background: Leafy spurge (Euphorbia esula) is a perennial weed that is considered glyphosate tolerant, which is partially attributed to escape through establishment of new vegetative shoots from an abundance of underground adventitious buds. Leafy spurge plants treated with sub-lethal concentrations of foliar-applied glyphosate produce new vegetative shoots with reduced main stem elongation and increased branching. Processes associated with the glyphosate-induced phenotype were determined by RNAseq using aerial shoots derived from crown buds of glyphosate-treated and -untreated plants. Comparison between transcript abundance and accumulation of shikimate or phytohormones (abscisic acid, auxin, cytokinins, and gibberellins) from these same samples was also done to reveal correlations.

Results: Transcriptome assembly and analyses confirmed differential abundance among 12,918 transcripts (FDR $\leq 0.05)$ and highlighted numerous processes associated with shoot apical meristem maintenance and stem growth, which is consistent with the increased number of actively growing meristems in response to glyphosate. Foliar applied glyphosate increased shikimate abundance in crown buds prior to decapitation of aboveground shoots, which induces growth from these buds, indicating that 5-enolpyruvylshikimate 3-phosphate (EPSPS) the target site of glyphosate was inhibited. However, abundance of shikimate was similar in a subsequent generation of aerial shoots derived from crown buds of treated and untreated plants, suggesting EPSPS is no longer inhibited or abundance of shikimate initially observed in crown buds dissipated over time. Overall, auxins, gibberellins (precursors and catabolites of bioactive gibberellins), and cytokinins (precursors and bioactive cytokinins) were more abundant in the aboveground shoots derived from glyphosate-treated plants.
\end{abstract}

Conclusion: Based on the overall data, we propose that the glyphosate-induced phenotype resulted from complex interactions involving shoot apical meristem maintenance, hormone biosynthesis and signaling (auxin, cytokinins, gibberellins, and strigolactones), cellular transport, and detoxification mechanisms.

Keywords: Bud dormancy, Branching, Glyphosate, Phytohormones, Shikimate, Transcriptomics, RNAseq

\footnotetext{
* Correspondence: james.anderson@ars.usda.gov

'United States Department of Agriculture, Agricultural Research Service,

Sunflower and Plant Biology Research, Fargo, ND 58102, USA

Full list of author information is available at the end of the article
} 


\section{Background}

After commercialization of glyphosate [N-(phosphonomethyl)glycine] in 1974, it has become one of the most common broad spectrum herbicides used in agricultural systems [1]. However, the evolution of glyphosateresistant weeds has increased the cost of weed management, reduced yield potential, and mandated the need for new weed management strategies [2]. No evidence of naturally occurring glyphosate-resistant plants was reported before the introduction of glyphosate-resistant transgenic crops, although several reports did indicate that biotypes of field bindweed (Convolvulus arvensis) and bermudagrass (Cynodon dactylon) were somewhat tolerant to glyphosate [3, 4]. Laticiferous perennial weeds such as hemp dogbane (Apocynum cannabinum), common milkweed (Asclepias syriaca), and leafy spurge (Euphorbia esula) have also been reported as glyphosate tolerant weeds [5-7]. Regardless, control of invasive perennial weeds in non-cultivated ecosystems of North America, including leafy spurge, generally requires integrated pest management programs that incorporate the use of glyphosate [8].

Reproduction of leafy spurge occurs through both seeds and vegetative propagules; however, persistence is mainly attributed to vegetative reproduction from an abundance of underground adventitious buds (UABs) [9]. Dormancy in UABs of leafy spurge also contributes to escape from conventional control measures and longterm management often requires follow up application with herbicides. Because glyphosate is a non-selective herbicide and impacts desired plants as well, in longterm management programs glyphosate is often used at lower than recommended rates or in combination with other herbicides. In fact, recommended rates of glyphosate for pastures, rangelands, roadsides, riverbanks and recreational areas $\left(\sim 1 \mathrm{~kg} \mathrm{ha}^{-1}\right)$ destroy the aboveground shoots of leafy spurge plants; however, it does little or no damage to UABs, and leafy spurge regenerates from these UABs. However, greater concentrations of glyphosate $\left(\sim 2-6 \mathrm{~kg} \mathrm{ha}^{-1}\right)$ generally cause sub-lethal effects in underground root system of leafy spurge; these higher rates still do not destroy the plants completely, but induce uncontrolled growth patterns (e.g., tillering and branching) from UABs in following generations, similar to the glyphosate-induced tillering observed in quackgrass (Agropyron repense) and common milkweed [10, 11]. Further, the effects of glyphosate on leafy spurge [12] were proposed to involve glyphosate's effect on release of apical dominance in lateral buds similar to that observed in sorghum (Sorghum bicolor), soybean (Glycine max), and pea (Pisum sativum), which have been linked to changes in auxin levels and transport [13, 14].

Translocation of glyphosate to the apical meristems, root meristems, and underground reproductive organs of perennial plants [15] inhibits nuclear encoded and chloroplast localized [16] 5-enolpyruvylshikimate-3-phosphate synthase (EPSPS) of the shikimate biosynthetic pathway $[17,18]$. Glyphosate's known mode of action occurs by inhibiting the EPSPS-catalyzed conversion of shikimate-3phosphate (S3P) to 5-enolpyruvylshikimate 3-phosphate (EPSP) by forming an EPSPS-S3P-glyphosate complex that competes for phosphoenolpyruvate binding [19-21]. These are critical steps for the production of chorismate, which is a precursor of aromatic amino acids (phenylalanine, tyrosine and tryptophan), auxin, and many other secondary products essential for plant growth and development. Thus, the glyphosate-induced inhibition of EPSPS reduces chorismate production leading to increased accumulation of shikimate [22]. However, beyond the known mode of action, the impact of glyphosate-treatment on transcriptional regulation has mainly focused on leaf tissues exposed to glyphosate in annual [23-25] and perennial grass species [26, 27]. Sub-lethal concentrations of foliar applied glyphosate also results in new shoot growth from UABs that produce a phenotype with reduced main stem elongation and increased branching from axillary bud outgrowth [28]. Thus, investigating glyphosate's impact on molecular processes and phytohormones affecting vegetative regrowth from UABs could provide new insights for novel weed management solutions.

The impact of foliar applied glyphosate has already provided some insights into the involvement of molecular processes associated with auxin, ethylene, and gibberellic acid (GA) biosynthesis and signaling pathways in crown buds of leafy spurge [28]. The most significant changes observed in these UABs were for ENT-COPALYL DIPHOSPHATE SYNTHETASE 1, which is involved in a committed step for GA biosynthesis, and auxin transporters including PIN-FORMED (PINS), PIN-LIKES (PILS) and ATP-BINDING CASSETTE (ABC) TRANSPORTERS. Further, most of the significantly affected processes were associated with the endoplasmic reticulum, suggesting that this organelle plays some role in cellular physiology in response to glyphosatetreatment in leafy spurge. However, since Doğramacı et al. [28] only examined a select set of transcripts from UABs, it may not reflect the effects of foliar applied glyphosate on global gene expression or actual changes in phytohormone and shikimate levels. Thus, to gain further insights into glyphosate's impact on molecular processes associated with phenotypes showing reduced stem elongation and increased branching due to axillary bud outgrowth, our objectives were 1) using RNAseq to determine global transcriptome abundance in aerial tissues derived from crown buds of glyphosate-treated and -untreated leafy spurge, 2) obtain shikimate and phytohormone concentration profiles from the same samples, and 3) elucidate relationships between transcriptome, shikimate, and phytohormone profiles to identify molecular processes that are altered by glyphosate. 


\section{Results}

Vegetative growth and phenotypic changes in response to glyphosate

Initiation of new vegetative shoot growth from crown buds following foliar glyphosate-treatment does not occur until the directly treated aerial tissues are decapitated [28], suggesting that paradormancy in crown buds is maintained, to some extent, post-treatment by apical dominance [29, 30]. However, after decapitation of aerial tissues $(7 \mathrm{~d}$ posttreatment), stem elongation of new vegetative shoots derived from crown buds of glyphosate-treated plants was reduced $(P<0.05)$ compared to controls (Fig. 1$)$, and the new shoots had increased branching. This phenotype was observed in at least three subsequent shoot generations, i.e., new aerial shoots derived from UABs present on the root system of the treated plants (see Additional file 1).

\section{Transcriptome changes in aerial tissues}

Transcriptome analyses (see Additional file 2) revealed that 12,918 transcripts had significant changes in abundance (FDR $\leq 0.05$ ) and 6,239 of these transcripts had significant changes $\geq 2$-fold in either direction; 3,632 decreased and 2,607 increased abundance in glyphosatetreated samples relative to controls. Of the 12,918 differentially expressed genes, 9,283 transcripts had similarity (BlastX hits at E values $<10 \mathrm{E}-3$ ) to genes in the Arabidopsis database (www.arabidopsis.org). Therefore, leafy spurge transcripts discussed throughout this manuscript are based on the most homologous match to Arabidopsis (see Additional file 2). Quantitative real-time PCR (qRT-PCR) based on a select set of genes (see Additional file 3) was used to validate the reliability of the RNAseq data, which revealed a similar trend in expression patterns - with the exception of CKX1. Additionally, Pearson's (P-value = $5.1 \mathrm{E}-05)$ or Spearman's (P-value $=0.012)$ correlation coefficients confirmed significant correlation between RNAseq and qRT-PCR data and validated use of the global transcript dataset.

\section{Shikimate abundance and chorismate biosynthesis}

In this study, the abundance of shikimate increased in tissues directly (aerial tissue) or indirectly (crown buds) exposed to glyphosate (Fig. 2), which is likely the result of glyphosate's inhibition of EPSPS [17, 18]. However, the abundance of shikimate in new aerial shoots (six weeks after growth-inducing decapitation) derived from crown buds of glyphosate-treated plants were similar to controls (Fig. 2). Additionally, abundance of transcripts (i.e., EPSPS, EMB1144, SK1) involved in various stages of chorismate biosynthesis had little change in amplitude (Table 1).

\section{Glyphosate-treatment impacts molecular mechanisms regulating the shoot apical meristem}

Sub-network enrichment analysis (SNEA) identified numerous over-represented ontologies among transcripts with increased or decreased abundance (see Additional file 4) in aerial shoots derived from crown buds of glyphosatetreated plants. An overview of the SNEA data indicated that hubs associated with increased transcript abundance

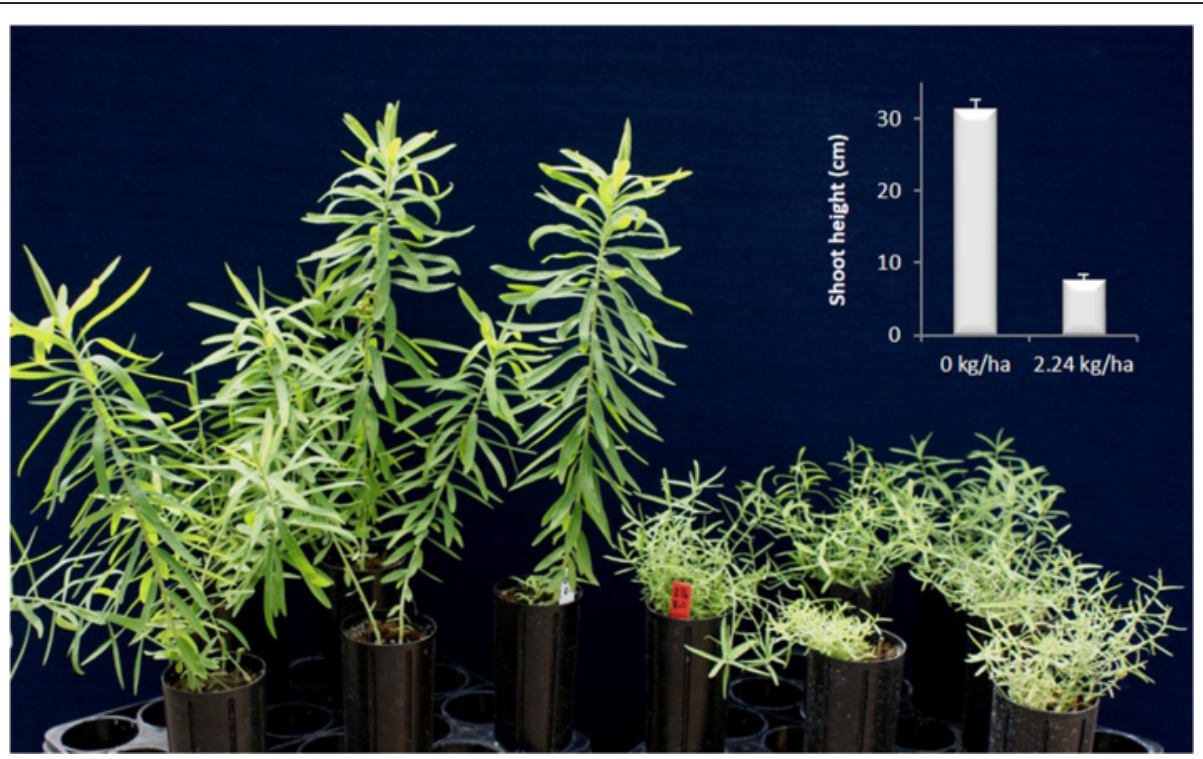

Fig. 1 Vegetative growth from crown buds of leafy spurge post glyphosate-treatment. After foliar glyphosate-treatment i.e., 0 kg ha ${ }^{-1}$ as controls (left) or $2.24 \mathrm{~kg} \mathrm{ha}^{-1}$ (right), plants were maintained for seven days under growth-conducive conditions and aerial tissues were decapitated to induce vegetative growth. Image and embedded chart show a significant reduction in vegetative growth six weeks post-decapitation. Vertical bars in the embedded chart indicate $95 \%$ confidence limits 

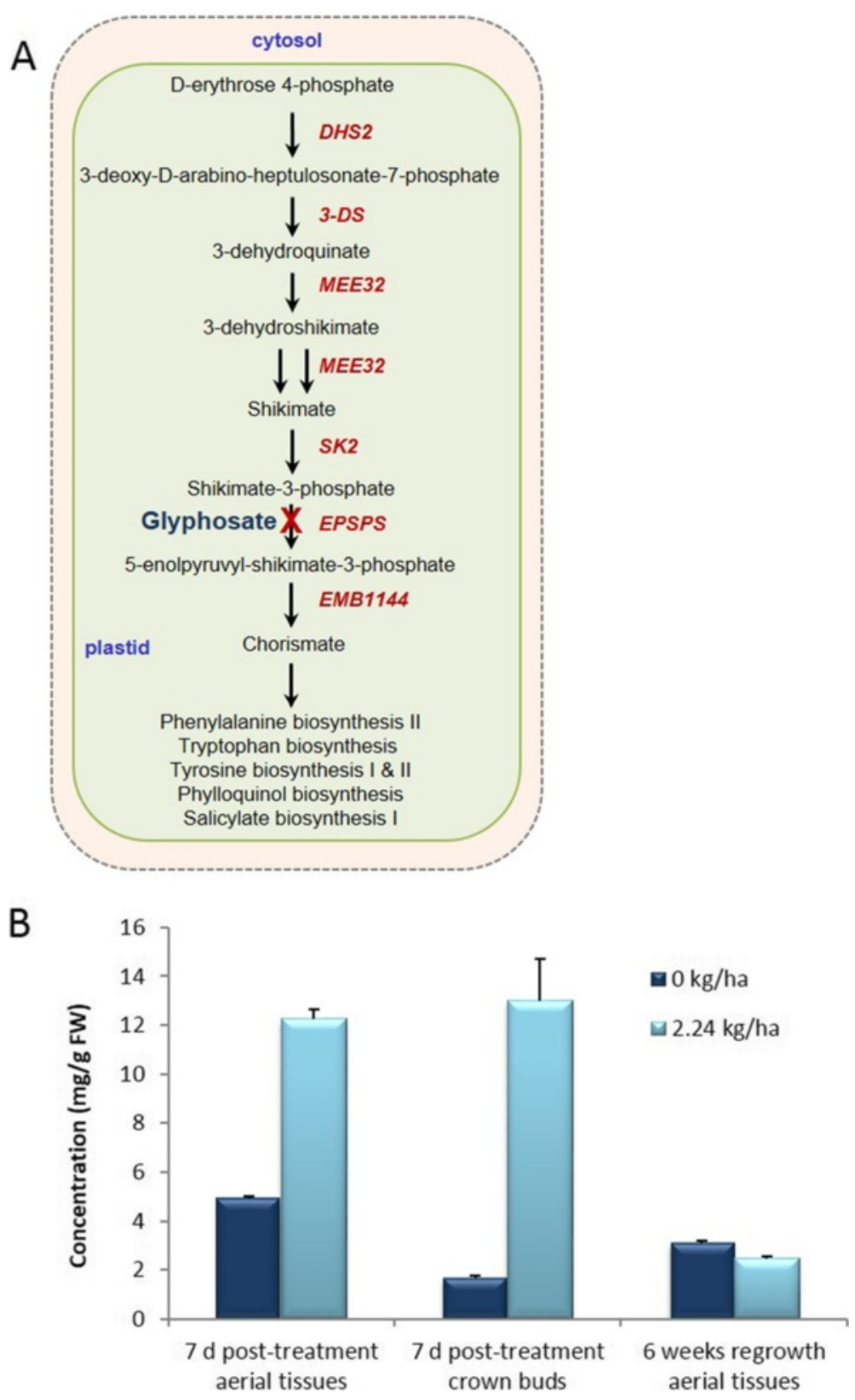

Fig. 2 Simplified shikimate/chorismate biosynthesis pathway, and shikimate abundance in leafy spurge tissues after glyphosate-treatment. (a) The pathway links the metabolism of carbohydrates to the biosynthesis of the aromatic amino acids (phenylalanine, tyrosine and tryptophan). The pathway is specific to microorganisms and plants; in plants the pathway appears to occur in plastids. Glyphosate is known to inhibit 5-enolpyruvylshikimate3-phosphate synthase (EPSPS) of the chorismate biosynthetic pathway. Red italic text indicates the genes involved in particular step/s of the pathway. (b) Shikimate abundance 7 days (d) post-treatment in aerial tissues which were directly exposed to glyphosate, in crown buds which were indirectly exposed to glyphosate $7 \mathrm{~d}$ post-treatment, and in aerial tissues derived from crown buds of foliar glyphosate-treated leafy spurge plants after decapitation (7 d post-treatment) and regrowth for six weeks. Shikimate abundance data represent the mean of four biological and two technical replicates obtained from fresh tissue (FW); vertical bars indicate \pm SE of the mean

are involved with numerous processes (e.g., cell cycle, cell differentiation and proliferation, cytokinesis, DNA replication, organ formation), proteins (e.g., ASYMMETRIC LEAVES1/2, CLAVATA3, CUP-SHAPED COTYLEDON1/2, E2F TRANSCRIPTION FACTOR,
KNOTTED-LIKE FROM ARABIDOPSIS THALIANA1, SHOOT MERISTEMLESS, WUSCHEL), and small molecules (i.e., brassinolide, cytokinin) associated with shoot apical meristem (SAM) maintenance. However, with the exception of the process 'stem growth' (see 
Table 1 Changes in abundance of transcripts involved in chorismate, auxin and strigolactone biosynthesis/signaling

\begin{tabular}{|c|c|c|c|c|c|}
\hline Category & Gene ID Abv. & Gene ID & $\log 2$ FC & TAIR ID & Component number \\
\hline Chorismate & EMB1144 & EMB1144, EMBRYO DEFECTIVE 1144 & 0.44 & AT1G48850.1 & comp72334_c0 \\
\hline \multirow[t]{2}{*}{ biosynthesis } & EPSPS & 5-ENOLPYRUVYLSHIKIMATE-3-PHOSPHATE SYNT. & 0.82 & AT2G45300.1 & comp78915_c0 \\
\hline & SK1 & SHIKIMATE KINASE 1 & 1.08 & AT2G21940.5 & comp71816_c0 \\
\hline Tryptophan & TSB2/TRP2 & TRYPTOPHAN SYNTHASE BETA-SUBUNIT 2 & -3.69 & AT4G27070.1 & comp79735_c0 \\
\hline biosynthesis & TSBTYPE2 & TRYPTOPHAN SYNTHASE BETA TYPE 2 & 1.31 & AT5G38530.1 & comp76554_c0 \\
\hline Auxin & CYP79B2 & CYTOCHROME P450, FAMILY 79 & -4.59 & AT4G39950.1 & comp78594_c0 \\
\hline \multirow[t]{4}{*}{ biosynthesis } & CYP83B1 & CYTOCHROME P450, FAMILY 83 & -2.28 & AT4G31500.1 & comp82508_c1 \\
\hline & TAA1 & TRYPTOPHAN AMINOTRANSFERASE ARABIDOPSIS1 & 4.73 & AT1G70560.1 & comp56536_c0 \\
\hline & YUC4 & YUCCA 4 & 2.37 & AT5G11320.1 & comp74711_c0 \\
\hline & YUC9 & YUCCA 9 & 3.12 & AT1G04180.1 & comp73458_c0 \\
\hline Auxin response & ARF2 & AUXIN RESPONSE FACTOR 2 & -1.16 & AT5G62000.3 & comp82702_c0 \\
\hline \multirow[t]{4}{*}{ factors } & ARF5 & AUXIN RESPONSE FACTOR 5 & 1.86 & AT1G19850.1 & comp81090_c0 \\
\hline & ARF6 & AUXIN RESPONSE FACTOR 6 & 1.05 & AT1G30330.1 & comp81172_c0 \\
\hline & ARF16 & AUXIN RESPONSE FACTOR 16 & -1.34 & AT4G30080.1 & comp72272_c0 \\
\hline & ARFP & AUXIN-RESPONSIVE FAMILY PROTEIN & -1.68 & AT5G35735.1 & comp76581_c1 \\
\hline \multirow[t]{7}{*}{ Auxin response } & IAA19 & INDOLE-3-ACETIC ACID INDUCIBLE 19 & 2.07 & AT3G15540.1 & comp65987_c0 \\
\hline & IAA26 & INDOLE-3-ACETIC ACID INDUCIBLE 26 & 1.49 & AT3G16500.1 & comp76858_c0 \\
\hline & IAA29 & INDOLE-3-ACETIC ACID INDUCIBLE 29 & -1.86 & AT4G32280.1 & comp68748_c0 \\
\hline & LRP1 & LATERAL ROOT PRIMORDIUM 1 & 3.26 & AT5G12330.4 & comp80582_c0 \\
\hline & SAUR32 & SMALL AUXIN UPREGULATED RNA 32 & -1.92 & AT2G46690.1 & comp72184_c0 \\
\hline & SAUR55 & SMALL AUXIN UPREGULATED RNA 55 & -1.42 & AT5G50760.1 & comp76265_c0 \\
\hline & SAUR59 & SMALL AUXIN UPREGULATED RNA 59 & -1.34 & AT3G60690.1 & comp73582_c0 \\
\hline Auxin & LAX2 & LIKE AUXIN RESISTANT 2 & 1.84 & AT2G21050.1 & comp74023_c1 \\
\hline \multirow[t]{5}{*}{ transporters } & LAX3 & LIKE AUXIN RESISTANT 3 & 1.01 & AT1G77690.1 & comp78151_c1 \\
\hline & PID & PINOID & 2.01 & AT2G34650.1 & comp81377_c0 \\
\hline & PIN1 & PIN-FORMED 1 & 1.82 & AT1G73590.1 & comp75801_c0 \\
\hline & PIN1 & PIN-FORMED 1 & 1.38 & AT1G73590.1 & comp80021_c0 \\
\hline & ABCB19 & ATP-BINDING CASSETTE B19 & 2.39 & AT3G28860.1 & comp83655_c0 \\
\hline Auxin conjugate & IAR3 & IAA-ALANINE RESISTANT 3 & -1.95 & AT1G51760.1 & comp74098_c0 \\
\hline metabolism & ILL6 & IAA-LEUCINE RESISTANT (ILR)-LIKE GENE 6 & -1.30 & AT1G44350.1 & comp77344_c0 \\
\hline Strigolactone & MAX1 & MORE AXILLARY BRANCHES 1/CYTOCHROME P450 & 0.64 & AT2G26170.1 & comp73668_c0 \\
\hline biosynthesis & MAX3 & MORE AXILLARY BRANCHES 3 & 1.52 & AT2G44990.1 & comp68151_c0 \\
\hline Strigolactone sig. & MAX2 & MORE AXILLARY BRANCHES 2 & -0.28 & AT2G42620.1 & comp84166_c0 \\
\hline
\end{tabular}

Transcript changes after foliar glyphosate treatment $\left(2.24 \mathrm{~kg} \mathrm{ha}^{-1}\right)$ compared to controls in aerial tissues derived from crown buds of leafy spurge. The Arabidopsis Information Resource was used to annotate homologs of leafy spurge transcripts (TAIR ID), to obtain gene IDs and abbreviations (Abv.); values represent $\log 2$ fold changes (FC)

Additional file 4), most hubs associated with decreased transcript abundance are involved in stress responses (e.g., apoptosis, photoinhibition, protein degradation, ROS generation, and virulence and xenobiotic clearance).

\section{Phytohormone profiling and abundance of associated transcripts}

Many of the aforementioned processes involved in SAM maintenance are regulated by phytohormone signaling and cross-talk [31, 32]. Indeed, previous studies [28] confirmed that pathways associated with phytohormone biosynthesis or signaling are impacted in crown buds of glyphosate-treated plants. To obtain a better understanding for the phenotypes observed in this study (Fig. 1), which could not be attributed to shikimate levels (Fig. 2) or transcripts involved in chorismate biosynthesis (Table 1), we quantified the abundance of phytohormones (see Additional file 5) in the vegetative shoots derived from crown buds of glyphosate-treated and control plants and their correlation to global transcriptome abundance. 


\section{Auxin abundance and associated transcripts}

New aerial tissues originating from crown buds of glyphosate-treated plants had an increased abundance of auxins (Fig. 3), mainly represented by biologically active indole-3-acetic acid (IAA) and smaller amounts of IAAconjugates aspartic acid (IAA-Asp) and glutamic acid (IAA-Glu). Noteworthy, the IAA precursor indole-3butyric acid (IBA) is present in untreated controls, but was not detectable in tissues derived from treated plants (Fig. 3). Abundance of transcripts involved in the tryptophan biosynthetic pathway (the main precursor of auxin) had varied expression patterns (Table 1). However, with the exception of transcripts homologous to Arabidopsis TSB2 (AT4G27070, decreased abundance; Table 1) and TSBTYPE2 (AT5G38530, increased abundance; Table 1), the majority of transcripts involved in tryptophan biosynthesis did not show significant changes in aerial tissues derived from crown buds of glyphosate-treated plants (see Additional file 2).

Tryptophan-dependent IAA biosynthesis is proposed to diverge into four pathways in plants [33,34], which include the indole-3-acetamide (IAM), the indole-3pyruvic acid (IPA), the tryptamine (TAM), and the indole-3-acetaldoxime (IAOX) pathways (Fig. 3). In subsequent-generations of aerial shoots obtained from crown buds of glyphosate-treated plants, transcripts homologous to Arabidopsis genes involved in the IPA pathway had increased abundance (TAA1, YUC4, YUC9; Table 1), whereas transcripts involved in the IAOX (CYP79B2, CYP83B1; Table 1) pathway had decreased abundance and no significant changes were observed for transcripts in the TAM and IAM pathways. Although overexpressing CYP79B2 in Arabidopsis results in increased levels of free auxin [35], in this study, auxin levels were increased (Fig. 3) even though transcript abundance for a leafy spurge homolog of CYP79B2 (of the IAOX pathway) was significantly decreased $(-4.59$ $\log 2$-fold; Table 1). Thus, the results presented in this study indicate that auxin is likely synthesized through the IPA pathway in subsequent generations of aerial tissues derived from plants exposed to glyphosate.

The increased abundance of auxin and/or its conjugates in response to glyphosate correlates well with the significant changes observed for transcripts homologous to Arabidopsis genes involved in auxin responses, which have either increased (ARF5, ARF6, GH3.1, IAA19, IAA26, LRP1) or decreased (ARF2, ARF16, ARFP, IAA29, SAUR32, SAUR55, SAUR59) abundance (Table 1). Other homologs of interest included several auxin transporters $(A B C B 19$, $L A X 2$, LAX3, PID, PIN1), which have a significant increase in transcript abundance. Although strigolactone abundance was not measured in this study, several homologs of transcripts involved in strigolactone biosynthesis (MAX1 and $M A X 3)$ were increased; whereas, abundance of transcript involved in downstream strigolactone signaling (MAX2) was decreased. Strigolactones can inhibit branching by depleting auxin transporters such as PIN1 [31, 32]. Thus, assuming these transcripts perform similar function in leafy spurge, the increased abundance of a transcript homologous to Arabidopsis PIN1 (Table 1), along with the increased branching observed in response to glyphosate treatment (Fig. 1) suggest that strigolactone biosynthesis or signaling are negatively impacted.

\section{Cytokinins and cell division}

Aerial shoots derived from crown buds of foliar glyphosatetreated plants were more abundant in precursors (c-ZR, $\mathrm{t}-\mathrm{ZR}, \mathrm{dhZR}, \mathrm{PR})$ and bioactive cytokinins ( $\mathrm{t}-\mathrm{Z}, \mathrm{dhZ}$ ) than untreated controls (Fig. 4). Although larger amounts of cZOG (a cytokinin catabolism product of c-Z) were present in control plants, a significant level of c-ZOG was also observed in glyphosate-treated plants. Aerial shoots derived from crown buds of glyphosate-treated plants also have increased (AK2, APT2, APT4, IPT3, LOG5), and decreased (LOG1, LOG5, LOG7) abundance of transcripts homologous to Arabidopsis genes involved in cytokinin biosynthesis (Table 2), which correlates well with the increased abundance of precursor and bioactive cytokinins observed in this study (Fig. 4). Likewise, decreased abundance of transcripts involved in cytokinin metabolism (CKX3), UGT73C1, UGT74E2) are also consistent with the levels of bioactive and catabolized cytokinins. Transcripts responsive to cytokinins had both increased (AHP1, ARR3) or decreased $(A H K 5)$ abundance. Because cytokinins also play a positive role in branching [31], cell division [36], and regulation of auxin synthesis in Arabidopsis [37], the abundance of bioactive cytokinins in a subsequent generation of aerial tissue may also have some bearing on the glyphosateinduced increased branching and abundance of transcripts homologous to Arabidopsis genes involved in the cell cycle (CDC2A, CDKB1;2, CYC1B, CYCA3;2, CYCA3;4, CYCB1;4, CYCB3;1, CYCD1;1, CYCD3;1) in this study (Table 2).

\section{GA abundance and associated transcripts}

Total GAs (precursors and catabolites of bioactive GA) were more abundant in aerial shoots derived from crown buds of glyphosate-treated plants (Fig. 5). The GAs detected (i.e., GA19, GA24, GA34, GA53) belong to either the early 13-hydroxylation pathway or to the nonhydroxylation pathway. The increased 13-hydroxylation pathway products G19 and G53 (precursors of biologically active GA1) suggests that some components of the GA biosynthetic pathway are stimulated in subsequent generations of aerial tissues from plants exposed to glyphosate. However, the increased abundance of GA34 (catabolism product of GA4) indicates that bioactive GA4 must have been produced in aerial tissues but is rapidly catabolized. The increased abundance of GA 


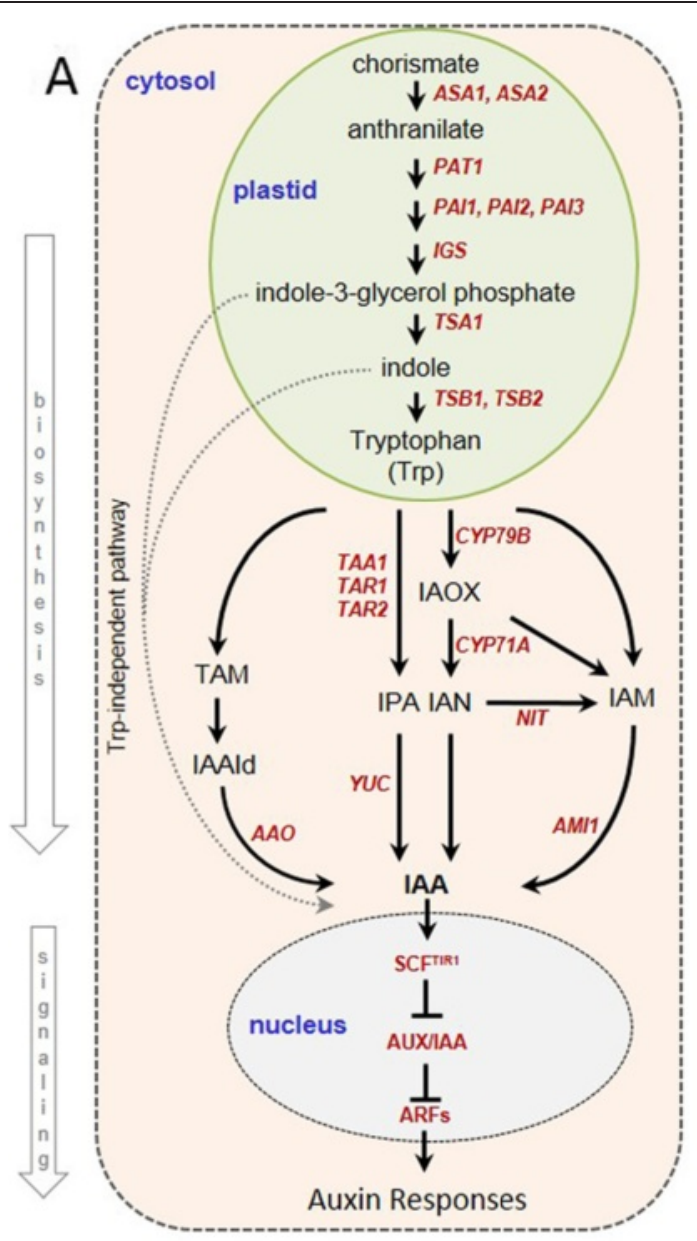

B

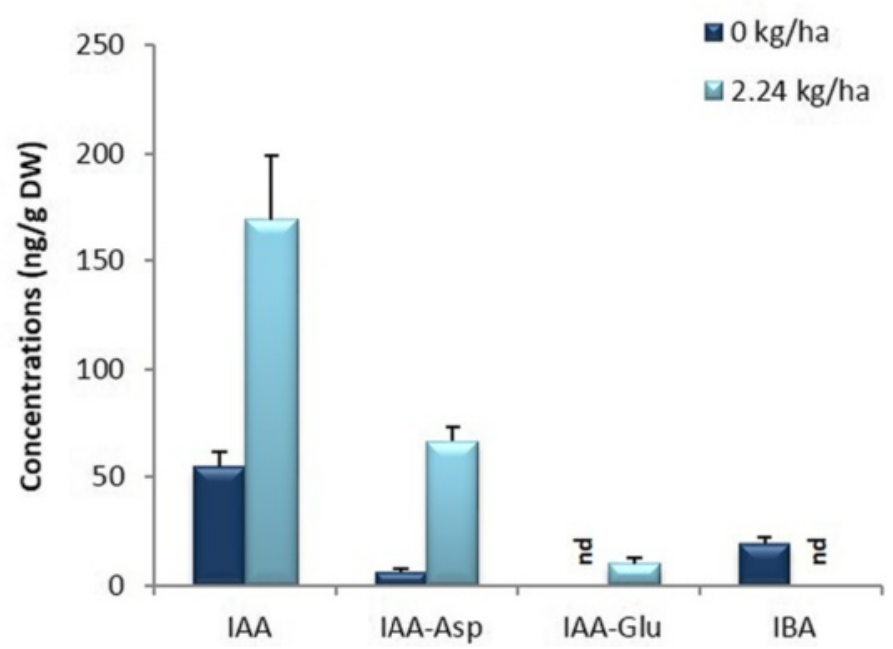

Fig. 3 Simplified auxin biosynthesis and signaling pathway in plants, and abundance of auxin profiles in aerial tissues derived from crown buds of glyphosate-treated leafy spurge. (a) Two major pathways have been proposed for auxin biosynthesis in plants, i.e., tryptophan (Trp)-dependent and -independent pathways. Several Trp-dependent auxin biosynthesis pathways have been proposed, i.e. the tryptamine (TAM), the indole-3-pyruvic acid (IPA), the indole-3-acetaldoxime (IAOX), and the indole-3-acetamide (IAM) pathways. Indole-3-glycerol phosphate is the branching point of the Trp-independent route. Red italic text indicates the genes involved in particular step/s of the pathway. (b) Abundance of bioactive auxins (IAA, IBA) and auxin conjugates (IAA-Asp, IAA-Glu) in aerial tissues derived from crown buds of glyphosate-treated plants. Data represent the mean of four biological replicates obtained from lyophilized tissue (DW), 'nd' indicates 'not detectable'; vertical bars indicate \pm SE of the mean 


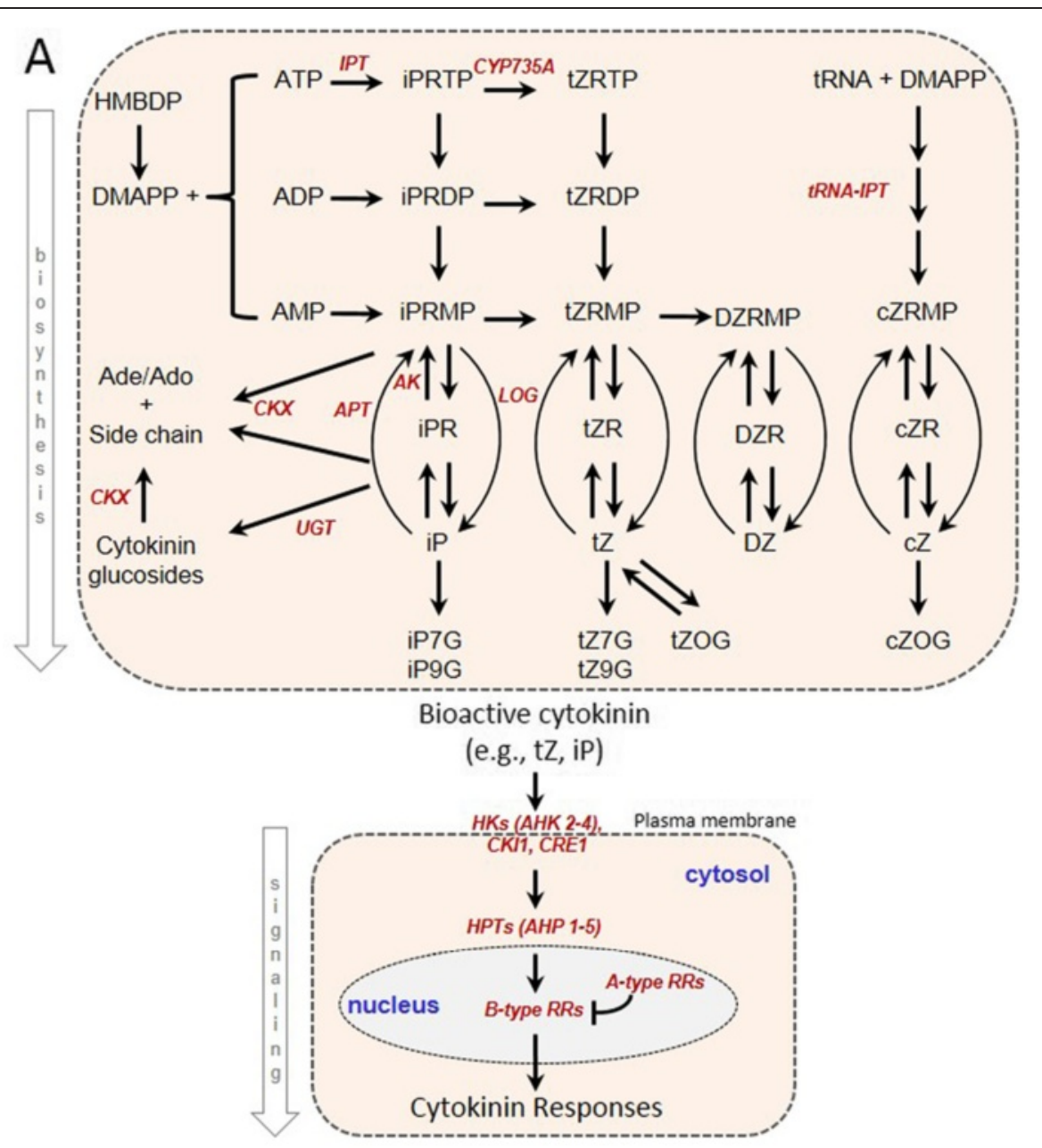

B

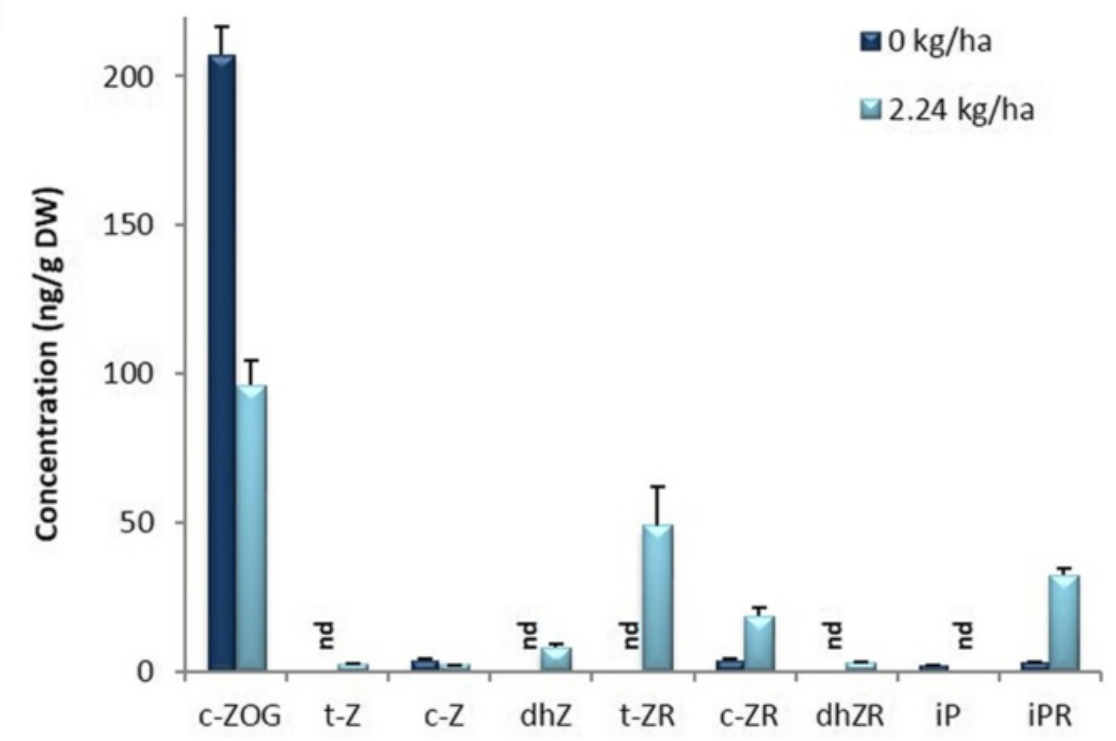

Fig. 4 (See legend on next page.) 
(See figure on previous page.)

Fig. 4 Simplified cytokinin biosynthesis and signaling pathway in plants, and abundance of cytokinin profiles in aerial tissues derived from crown buds of glyphosate-treated leafy spurge. (a) Adenosine phosphate-isopentenyltransferase (IPT) catalyzes the first step in the biosynthesis of isoprene cytokinins; dimethylallyl diphosphate (DMAPP) or hydroxymethylbutenyl diphosphate (HMBDP) may be used as prenyl donors, and ATP, ADP, or AMP may be used as substrates to produce diverse classes of cytokinins. In cytokinin signaling pathway, hybrid histidine protein kinases (HKs) serve as cytokinin receptors, histidine phosphotransfer proteins (HPTs) transmit the signal from HKs to nuclear response regulators (A- and B-type RRs). Red italic text indicates the genes involved in particular step/s of the pathway. (b) Abundance of cytokinin precursors (c-ZR, t-ZR, dZR, iPR), bioactive cytokinins ( $t-Z$, and dhZ), and cytokinin catabolism products (c-Z, c-ZOG) in aerial tissues derived from crown buds of glyphosate-treated plants. Data represent the mean of four biological replicates obtained from lyophilized tissue (DW), 'nd' indicates 'not detectable'; vertical bars indicate \pm SE of the mean

precursors in response to glyphosate seems consistent with the increased abundance of transcripts homologous to Arabidopsis genes $(K O, K S)$ involved in early steps of GA biosynthesis. However, the decreased abundance of a transcript homologous to Arabidopsis GA3OX1 (Table 3) might suggest that downstream biosynthetic steps involved in the conversion of precursors to bioactive GA are inhibited in response to glyphosate. The increased abundance of transcripts (GA2OX2,
GA2OX4) involved in catabolism of bioactive GA would also correlate well with the lack of bioactive GAs observed in response to glyphosate in this study. Further, transcripts of homologs known to inhibit downstream GA-signaling [38], such as the GRAS family (SCL28, SCL32) of transcription factors or the related Scarecrow family of transcription factors involved in asymmetric cell division (SCR, SHR), have increased abundance in response to glyphosate (Table 3 ).

Table 2 Changes in abundance of transcripts involved in cytokinin biosynthesis/response and cell cycle

\begin{tabular}{|c|c|c|c|c|c|}
\hline Category & Gene ID Abv. & Gene ID & $\log 2 \mathrm{FC}$ & TAIR ID & Component number \\
\hline Cytokinin & AK2 & ADENOSINE KINASE 2 & 1.50 & AT5G03300.1 & comp71044_c0 \\
\hline \multirow[t]{7}{*}{ biosynthesis } & APT2 & ADENINE PHOSPHORIBOSYL TRANSFERASE 2 & 4.94 & AT1G80050.1 & comp71670_c0 \\
\hline & APT4 & ADENINE PHOSPHORIBOSYL TRANSFERASE 4 & 1.95 & AT4G12440.2 & comp66282_c0 \\
\hline & IPT3 & ISOPENTENYLTRANSFERASE 3 & 2.04 & AT3G63110.1 & comp60518_c0 \\
\hline & LOG1 & LONELY GUY 1 & -1.00 & AT2G28305.1 & comp62804_c0 \\
\hline & LOG5 & LONELY GUY 5 & 2.35 & AT4G35190.1 & comp70636_c0 \\
\hline & LOG5 & LONELY GUY 5 & -1.79 & AT4G35190.1 & comp74853_c0 \\
\hline & LOG7 & LONELY GUY 7 & -1.36 & AT5G06300.1 & comp62804_c1 \\
\hline Cytokinin & CKX3 & CYTOKININ OXIDASE 3 & -1.56 & AT5G56970.1 & comp79554_c0 \\
\hline \multirow[t]{2}{*}{ metabolism } & UGT73C1 & UDP-GLUCOSYL TRANSFERASE 73C1 & -1.01 & AT2G36750.1 & comp66494_c1 \\
\hline & UGT74E2 & URIDINE DIPHOSPHATE GLYCOSYLTRANSFERASE 74E2 & -1.49 & AT1G05680.1 & comp70147_c0 \\
\hline Cytokinin & AHK5 & HISTIDINE KINASE 5 & -1.82 & AT5G10720.1 & comp78257_c0 \\
\hline \multirow[t]{2}{*}{ response } & AHP1 & HISTIDINE-CONTAINING PHOSPHOTRANSMITTER 1 & 1.87 & AT3G21510.1 & comp68321_c1 \\
\hline & ARR3 & ARABIDOPSIS RESPONSE REGULATOR 3 & 2.35 & AT1G59940.1 & comp69766_c0 \\
\hline \multirow[t]{11}{*}{ Cell cycle } & CDC2A & CELL DIVISION CONTROL 2 & 1.36 & AT3G48750.1 & comp73867_c0 \\
\hline & $\mathrm{CDKB} 1 ; 2$ & CYCLIN-DEPENDENT KINASE B1;2 & 2.65 & AT2G38620.2 & comp68143_c0 \\
\hline & $\mathrm{CDKB} 2 ; 2$ & CYCLIN-DEPENDENT KINASE B2;2 & 2.49 & AT1G20930.1 & comp69392_c0 \\
\hline & CYC1B & CYCLIN B 1;2 & 2.65 & AT5G06150.1 & comp73117_c0 \\
\hline & CYCA3;2 & CYCLIN-DEPENDENT PROTEIN KINASE 3;2 & 2.45 & AT1G47210.2 & comp62278_c0 \\
\hline & CYCA3;4 & CYCLIN A3;4 & 2.63 & AT1G47230.1 & comp80977_c0 \\
\hline & CYCB1;4 & CYCLIN B1;4 & 2.55 & AT2G26760.1 & comp66390_c0 \\
\hline & CYCB3;1 & CYCLIN B3;1 & 2.22 & AT1G16330.1 & comp77441_c0 \\
\hline & CYCD $1 ; 1$ & CYCLIN D1;1 & 1.24 & AT1G70210.1 & comp79632_c0 \\
\hline & CYCD3;1 & CYCLIN D3;1 & 1.54 & AT4G34160.1 & comp70052_c0 \\
\hline & CYCD3;2 & CYCLIN D3;2 & 1.46 & AT5G67260.1 & comp68903_c0 \\
\hline
\end{tabular}

Transcript changes after foliar glyphosate treatment $\left(2.24 \mathrm{~kg} \mathrm{ha}^{-1}\right)$ compared to controls in aerial tissues derived from crown buds of leafy spurge. The Arabidopsis Information Resource was used to annotate homologs of leafy spurge transcripts (TAIR ID), to obtain gene IDs and abbreviations (Abv.); values represent log2 fold changes (FC) 

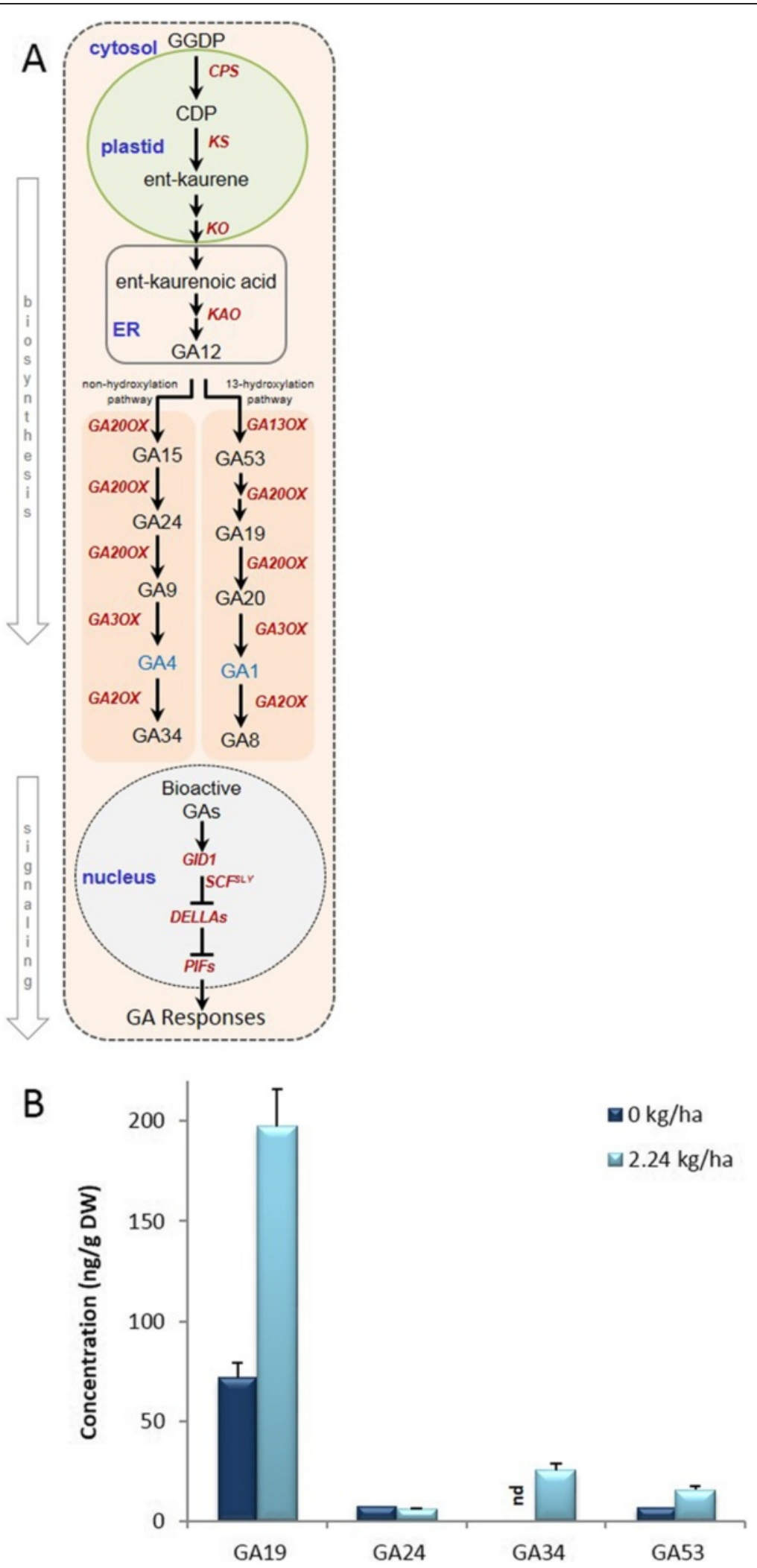

Fig. 5 (See legend on next page.) 
(See figure on previous page.)

Fig. 5 Simplified gibberellic acid (GA) biosynthesis and signaling pathway in plants, and abundance of GA profiles in aerial tissues derived from crown buds of glyphosate-treated leafy spurge. (a) GA biosynthesis occurs in three stages in different subcellular compartments: cyclization of geranylgeranyl diphosphate by copalyl diphosphate synthase (CPS) and ent-kaurene synthase (KS) to produce ent-kaurene in the plastids; conversion of ent-kaurene into GA12 via cytochrome P450 monooxygenases (e.g., KO, KAO) in the endoplasmic reticulum (ER); conversion of GA12 to bioactive forms of GA (e.g., GA1 and GA4 indicated with blue text) in the cytosol via 13-hydroxylation pathway or non-hydroxylation pathway. Red italic text indicates the genes involved in particular step/s of the pathway. (b) Abundance of GA precursors (GA19, GA24, GA53) and catabolism products (GA34). Data represent the mean of four biological replicates obtained from lyophilized tissue (DW), 'nd' indicates 'not detectable'; vertical bars indicate \pm SE of the mean

\section{ABA abundance and associated transcripts}

Bioactive ABA levels were similar in subsequent generations of aerial tissues derived from crown buds of foliar glyphosate-treated and control plants (Fig. 6). The only significant changes observed in response to glyphosate occurred for the main ABA metabolism pathway through 8'hydroxylation (Fig. 6), which leads to inactive phasic acid (PA) production and its conversion to diphaseic acid (DPA), and the secondary catabolism pathway leading to conjugation of ABA (ABAGE). Some transcripts homologous to Arabidopsis genes involved in $\mathrm{ABA}$ biosynthesis had both increased (ABA2, NCED3) and decreased (AAO4) abundance (Table 4) but did not seem to impact the abundance of bioactive ABA observed in treated or control plants. However, the decrease in abundance of transcripts involved in ABA catabolism (e.g., CYP707A3, UGT71B1) would be consistent with the decreased abundance of the ABA catabolites DPA and PA in glyphosatetreated plants. Transcripts involved in or responsive to ABA signaling in other systems had both increased (COR6.6, DREB1D, PLDALPHA1, RCAR10) and decreased (ABF1, AP2C1, CDPK1) transcript abundance. However, because changes in transcript abundance do not correlate to bioactive ABA levels, it is possible that some or all of these transcripts may be responsive to other phytohormones or stress-responses (see Additional file 2).

\section{Other phytohormones and growth related processes}

Although abundance of ethylene and jasmonic acid (JA) were not quantified in this study, significant changes in abundance of transcripts homologous to Arabidopsis genes involved in biosynthesis or signaling associated with these phytohormones were observed (Table 5). For example, transcripts involved in JA biosynthesis/signaling (JAR1, LOX2, WRKY40, WRKY50, WRKY70) mainly had decreased abundance (Table 5) but a significant increase in abundance of $S T 2 A$ and CYP94B1 was observed in response to glyphosate. ST2A encodes a hydroxyjasmonate sulfotransferase in Arabidopsis, which inactivates the function of JA [39]. Additionally, transcripts involved in ethylene biosynthesis (see Additional file 6) had decreased (ACS1, ACS6, ACS10) and increased (ACS11) abundance (Table 5) in subsequent generations of aerial tissue derived from crown buds of glyphosate-treated plants. These aerial

Table 3 Changes in abundance of transcripts involved in GA biosynthesis, catabolism and signaling

\begin{tabular}{|c|c|c|c|c|c|}
\hline Category & Gene ID Abv. & Gene ID & $\log 2 \mathrm{FC}$ & TAIR ID & Component number \\
\hline \multirow[t]{3}{*}{ GA biosynthesis } & GA3OX1 & GIBBERELLIN 3-OXIDASE 1 & -2.73 & AT1G15550.1 & comp57360_c0 \\
\hline & KO/CYP701A3 & ENT-KAURENE OXIDASE 1 & 1.09 & AT5G25900.1 & comp77748_c0 \\
\hline & KS & ENT-KAURENE SYNTHASE & 1.38 & AT1G79460.1 & comp72406_c0 \\
\hline \multirow[t]{4}{*}{ GA catabolism } & GA2OX1 & GIBBERELLIN 2-OXIDASE 1 & -1.38 & AT1G78440.1 & comp70621_c1 \\
\hline & GA2OX2 & GIBBERELLIN 2-OXIDASE 2 & 2.07 & AT1G30040.1 & comp72361_c0 \\
\hline & GA2OX4 & GIBBERELLIN 2-OXIDASE 4 & 3.20 & AT1G02400.1 & comp67827_c0 \\
\hline & GA2OX4 & GIBBERELLIN 2-OXIDASE 4 & 1.33 & AT1G02400.1 & comp76771_c0 \\
\hline GA mediated & GASA6 & GA-STIMULATED ARABIDOPSIS 6 & 3.50 & AT1G74670.1 & comp69402_c0 \\
\hline \multirow[t]{7}{*}{ signaling } & GASA9 & GA-STIMULATED ARABIDOPSIS 9 & 2.10 & AT1G22690.3 & comp64133_c0 \\
\hline & GASA11 & GA-STIMULATED ARABIDOPSIS 11 & -1.02 & AT2G18420.1 & comp74978_c0 \\
\hline & SCL14 & SCARECROW-LIKE 14 & -1.52 & AT1G07530.1 & comp81394_c0 \\
\hline & $\mathrm{SCL} 28$ & SCARECROW-LIKE 28 & 2.11 & AT1G63100.1 & comp83623_c0 \\
\hline & SCL32 & SCARECROW-LIKE 32 & 1.18 & AT3G49950.1 & comp65814_c0 \\
\hline & SCR & SCARECROW & 1.41 & AT3G54220.1 & comp80927_c1 \\
\hline & SHR & SHORT ROOT & 1.85 & AT4G37650.1 & comp70203_c1 \\
\hline
\end{tabular}

Transcript changes after foliar glyphosate treatment $\left(2.24 \mathrm{~kg} \mathrm{ha}^{-1}\right)$ compared to controls in aerial tissues derived from crown buds of leafy spurge. The Arabidopsis Information Resource was used to annotate homologs of leafy spurge transcripts (TAIR ID), to obtain gene IDs and abbreviations (Abv.); values represent $\log 2$ fold changes (FC) 


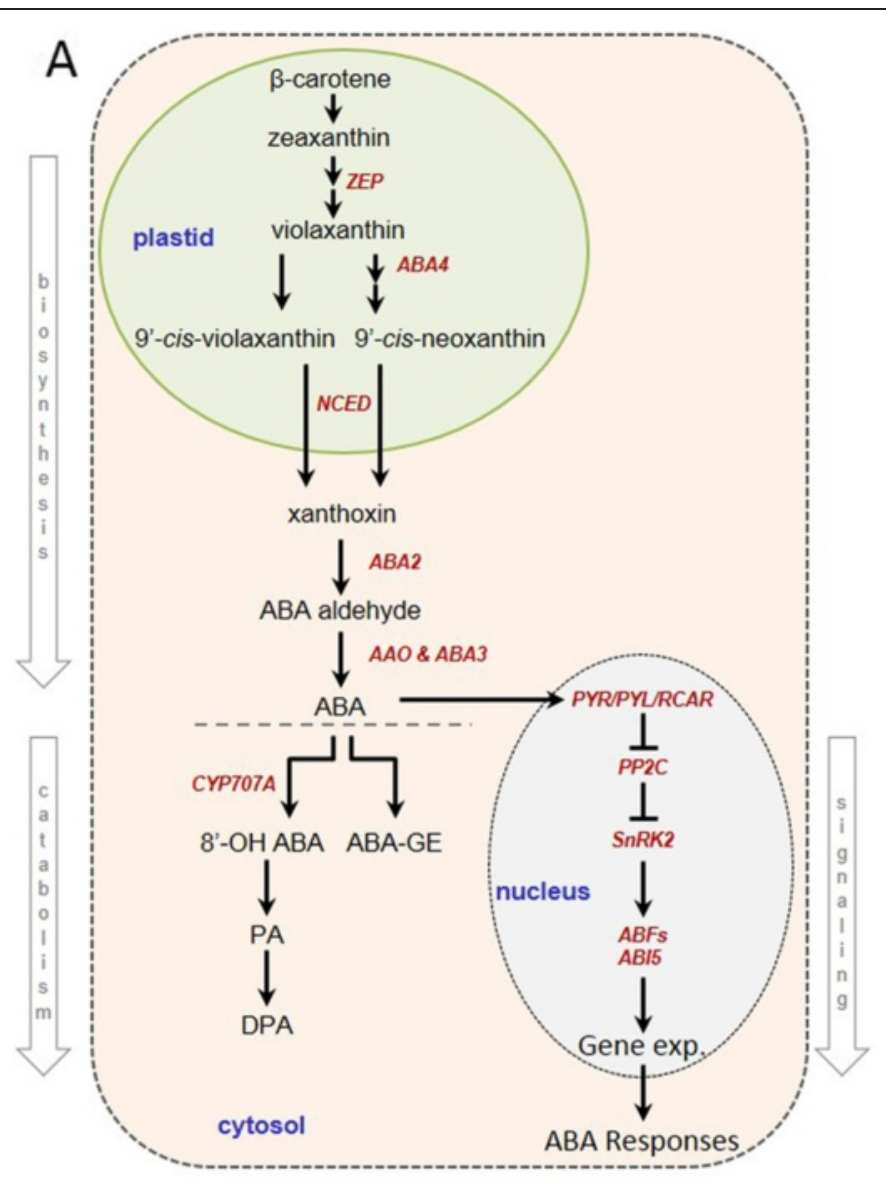

B

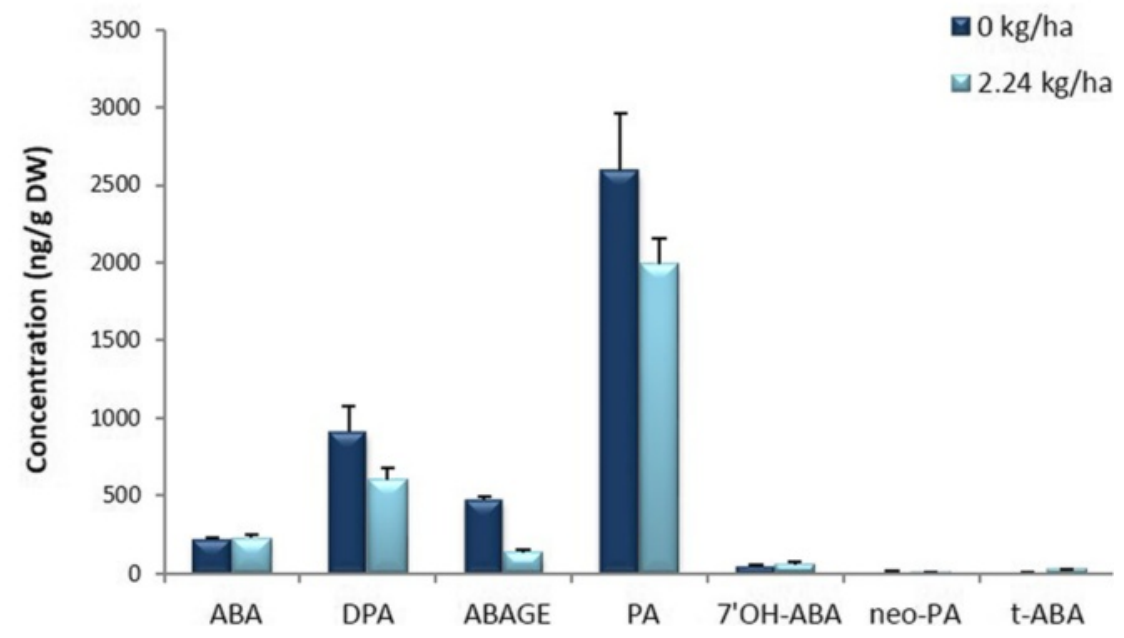

Figure 6 Simplified pathway of abscisic acid (ABA) biosynthesis and signaling in plants, and abundance of ABA profiles in aerial tissues derived from crown buds of glyphosate-treated leafy spurge. (a) ABA is synthesized from C40 carotenoids (e.g., $\beta$-carotene) via the oxidative cleavage to produce xanthoxin in the plastids; xanthoxin is converted to ABA-aldehyde and then to ABA in the cytoplasm. Red italic text indicates the genes involved in particular step/s of the pathway. (b) Abundance of ABA, and its metabolites and conjugates (PA, DPA, ABAGE, 7'OH-ABA, neo-PA, t-ABA). Data represent the mean of four biological replicates obtained from lyophilized tissue (DW); vertical bars indicate \pm SE of the mean 
Table 4 Changes in abundance of transcripts involved in ABA biosynthesis, catabolism and signaling

\begin{tabular}{|c|c|c|c|c|c|}
\hline Category & Gene ID Abv. & Gene ID & $\log 2 \mathrm{FC}$ & TAIR ID & Component number \\
\hline$\overline{\mathrm{ABA}}$ & $\mathrm{AAO4}$ & ALDEHYDE OXIDASE 4 & -1.31 & AT1G04580.1 & comp67916_c0 \\
\hline \multirow[t]{4}{*}{ biosynthesis } & $\mathrm{ABA} 2$ & ABA DEFICIENT 2 & 1.92 & AT1G52340.1 & comp64618_c0 \\
\hline & $\mathrm{ABA} 2$ & ABA DEFICIENT 2 & -1.06 & AT1G52340.1 & comp67801_c0 \\
\hline & ABA2 & ABA DEFICIENT 2 & 4.64 & AT1G52340.1 & comp69765_c0 \\
\hline & NCED3 & NINE-CIS-EPOXYCAROTENOID DIOXYGENASE 3 & 2.27 & AT3G14440.1 & comp62453_c0 \\
\hline ABA & CYP707A3 & CYTOCHROME P450, FAMILY 707 & -5.55 & AT5G45340.1 & comp48367_c0 \\
\hline \multirow[t]{2}{*}{ catabolism } & UGT71B1 & UDP-GLUCOSYL TRANSFERASE 71B1 & -1.35 & AT3G21750.1 & comp63205_c0 \\
\hline & UGT71B1 & UDP-GLUCOSYL TRANSFERASE 71B1 & -1.53 & AT3G21750.1 & comp78910_c1 \\
\hline $\mathrm{ABA}$ & ABF1 & ABSCISIC ACID RESPONSIVE ELEMENT-BINDING FAC 1 & -2.19 & AT1G49720.2 & comp81822_c0 \\
\hline \multirow[t]{7}{*}{ signaling } & $\mathrm{AP} 2 \mathrm{C} 1$ & PP2C-TYPE PHOSPHATASE & -1.58 & AT2G30020.1 & comp71725_c1 \\
\hline & CDPK1A & CALCIUM-DEPENDENT PROTEIN KINASE $1 \mathrm{~A}$ & -1.21 & AT1G74740.1 & comp82371_c2 \\
\hline & COR6.6 & COLD-RESPONSIVE 6.6 & 2.52 & AT5G15970.1 & comp63310_c0 \\
\hline & DREB1D & DEHYDRATION-RESPONSIVE ELEMENT-BINDING 1D & 1.30 & AT5G51990.1 & comp72894_c0 \\
\hline & HB6 & HOMEOBOX PROTEIN 6 & 1.07 & AT2G22430.1 & comp68807_c1 \\
\hline & PLDALPHA1 & PHOSPHOLIPASE D ALPHA 1 & 1.37 & AT3G15730.1 & comp79335_c0 \\
\hline & RCAR10 & REGULATORY COMPONENTS OF ABA RECEPTOR 10 & 2.37 & AT2G38310.1 & comp66032_c0 \\
\hline
\end{tabular}

Transcript changes after foliar glyphosate treatment $\left(2.24 \mathrm{~kg} \mathrm{ha}^{-1}\right)$ compared to controls in aerial tissues derived from crown buds of leafy spurge. The Arabidopsis Information Resource was used to annotate homologs of leafy spurge transcripts (TAIR ID), to obtain gene IDs and abbreviations (Abv.); values represent $\log 2$ fold changes (FC)

tissues also had mixed transcript abundance for ethylene responsive genes; ERF12, ERF13, RAP2.3, T16118.10, and TINY2 had increased transcript abundance, whereas ERF1, ERF6, ERF105, ERF110, and K22G18.1 had decreased transcript abundance (Table 5). Because exogenous application of ethylene precursor causes a dwarfed phenotype in subsequent generations derived from UABs of leafy spurge [40], the significant changes in ethyleneresponsive transcripts suggest that glyphosate likely affected ethylene biosynthesis and/or signaling pathways in UABs of leafy spurge, which could have some effect on the stunted phenotype observed in this study.

Some CYTOCHROME P45O MONOOXYGENASES (P450s) and UDP-GLUCOSYL/-GLYCOSYL TRANSFERASES (UGTs) are classified under phytohormone biosynthesis or signaling (Tables 1-5, and Additional file 2). However, numerous other members of these two families represent the largest number of differentially expressed transcripts (see Additional file 2) in subsequent generations of aerial tissues in response to glyphosate. Similarly, numerous ABC TRANSPORTERS and GLUTATHIONE $S$-TRANSFERASES (GSTS) had significant changes in transcript abundance with both increased and decreased patterns (Table 6, and Additional file 2).

\section{Discussion}

Direct exposure of leafy spurge aerial tissues to sub-lethal concentrations of glyphosate causes an indirect effect that impacts molecular processes in UABs prior to growth induction by decapitation [28]. In this study, reduced main stem elongation and increased branching was observed in four subsequent generations derived from UABs present in the same root system of treated plants (Fig. 1, and Additional file 1), and the effects of glyphosate on phenotype did not diminish in these generations. However, after four generations of vegetative growth no more UABs were left in the root system of these plants (grown in conetainers) to observe if the plants would ultimately outgrow the effects of glyphosate. Parallel studies performed under field conditions revealed that higher rates of foliar-applied glyphosate $\left(3\right.$ or $6 \mathrm{~kg} \mathrm{ha}^{-1}$ ) affects vegetative growth from UABs of leafy spurge and causes similar phenotypical alterations for at least two consecutive years after the glyphosate-treatment (Doğramaci et al. unpublished data). Sub-lethal rates of glyphosate have also been reported to induce similar phenotypes in annual species such as corn (Zea mays), cotton (Gossypium hirsutum), sorghum, and wheat (Triticum aestivum) [13, 41-43]. To gain insights on factors involved in these glyphosate-induced phenotypes, here we determined the effects of foliar applied glyphosate on the abundance of metabolites (shikimate and hormones) and their correlation to global transcript abundance in subsequent generation of aerial tissues.

\section{Glyphosate-treatment caused differential accumulation of shikimate}

Little information is available on the abundance of shikimate in underground buds or in subsequent generations 
Table 5 Changes in abundance of transcripts involved in ethylene and JA biosynthesis, metabolism and signaling

\begin{tabular}{|c|c|c|c|c|c|}
\hline Category & Gene ID Abv. & Gene ID & $\log 2 \mathrm{FC}$ & TAIR ID & Component number \\
\hline Ethylene & ACS1 & ACC SYNTHASE 1 & -2.48 & AT3G61510.1 & comp63647_c0 \\
\hline \multirow[t]{3}{*}{ biosynthesis } & ACS6 & ACC SYNTHASE 6 & -1.60 & AT4G11280.1 & comp81533_c0 \\
\hline & ACS10 & ACC SYNTHASE 10 & -1.94 & AT1G62960.1 & comp83189_c0 \\
\hline & ACS11 & ACC SYNTHASE 11 & 5.97 & AT4G08040.1 & comp68485_c0 \\
\hline \multirow[t]{10}{*}{ AP2/ERF TF } & ERF1 & ETHYLENE RESPONSE FACTOR 1 & -3.35 & AT3G23240.1 & comp63489_c0 \\
\hline & ERF6 & ETHYLENE RESPONSIVE ELEMENT BINDING FAC 6 & -1.22 & AT4G17490.1 & comp76450_c0 \\
\hline & ERF12 & ERF DOMAIN PROTEIN 12 & 1.63 & AT1G28360.1 & comp69972_c0 \\
\hline & ERF13 & ETHYLENE-RESPONSIVE ELEMENT BINDING FAC 13 & 3.33 & AT2G44840.1 & comp68474_c0 \\
\hline & ERF105 & ETHYLENE-RESPONSIVE ELEMENT BINDING FAC 105 & -2.05 & AT5G51190.1 & comp81745_c0 \\
\hline & ERF110 & ETHYLENE RESPONSE FACTOR 110 & -1.78 & AT5G50080.1 & comp78763_c0 \\
\hline & K22G18.1 & K22G18.1 & -1.94 & AT5G61890.1 & comp52489_c0 \\
\hline & RAP2.3 & RELATED TO AP2 3 & 1.40 & AT3G16770.1 & comp58768_c0 \\
\hline & T16|18.10 & $\mathrm{T} 16 \mid 18.10$ & 1.29 & AT4G32800.1 & comp68841_c0 \\
\hline & TINY2 & TINY2 & 1.95 & AT5G11590.1 & comp68230_c0 \\
\hline \multirow[t]{4}{*}{ JA biosynthesis } & AOS & ALLENE OXIDE SYNTHASE & 1.11 & AT5G42650.1 & comp61253_c0 \\
\hline & LOX2 & LIPOXYGENASE 2 & -2.50 & AT3G45140.1 & comp77454_c0 \\
\hline & LOX2 & LIPOXYGENASE 2 & -2.09 & AT3G45140.1 & comp79859_c0 \\
\hline & LOX2 & LIPOXYGENASE 2 & -2.11 & AT3G45140.1 & comp82248_c0 \\
\hline JA mediated & CYP94B1 & CYTOCHROME P450, FAMILY 94 & 1.62 & AT5G63450.1 & comp75229_c0 \\
\hline \multirow[t]{5}{*}{ signaling } & JAR1 & JASMONATE RESISTANT 1 & -1.26 & AT2G46370.2 & comp80290_c0 \\
\hline & WRKY40 & WRKY DNA-BINDING PROTEIN 40 & -1.94 & AT1G80840.1 & comp75129_c0 \\
\hline & WRKY50 & WRKY DNA-BINDING PROTEIN 50 & -2.96 & AT5G26170.1 & comp62445_c0 \\
\hline & WRKY70 & WRKY DNA-BINDING PROTEIN 70 & -1.39 & AT3G56400.1 & comp75789_c1 \\
\hline & ST2A & ARABIDOPSIS THALIANA SULFOTRANSFERASE 2A & 6.54 & AT5G07010.1 & comp85207_c0 \\
\hline
\end{tabular}

Transcript changes after foliar glyphosate treatment $\left(2.24 \mathrm{~kg} \mathrm{ha}^{-1}\right)$ compared to controls in aerial tissues derived from crown buds of leafy spurge. The Arabidopsis Information Resource was used to annotate homologs of leafy spurge transcripts (TAIR ID), to obtain gene IDs and abbreviations (Abv.); values represent log2 fold changes (FC)

derived from glyphosate-treated perennials, with the exception of glyphosate-induced accumulation of shikimate in sprouted tubers of the perennial weed purple nutsedge (Cyperus rotundus) [44]. Overall, changes in shikimate abundance in leafy spurge tissues after glyphosatetreatment (Fig. 2) were relatively low compared to those reported in other species $[45,46]$, but it is important to note that the rate used in this study had only a sub-lethal effect. Minor changes in abundance of transcripts involved in the chorismate biosynthetic pathway in aerial tissues (Table 1) are similar to that previously observed in crown buds of leafy spurge [28] or other weedy species such as palmer amaranth and horseweed following glyphosatetreatment $[46,47]$. The increased accumulation of shikimate in aerial tissues of leafy spurge directly treated with glyphosate or in crown buds that were indirectly exposed (Fig. 2) is not surprising, given that significant shikimate accumulation is detectable several days prior to visual injury in response to glyphosate-treatment in other species [48]. Regardless of their seasonal dormancy phase (i.e., para-, endo-, or eco-dormancy), UABs of leafy spurge are active and rapidly respond to environmental changes; in fact, during the shifts between seasonal phases there is some limited growth and development [49] suggesting UABs may serve as a sink tissue. We hypothesize that the increased abundance of shikimate in crown buds is due to either 1) translocation of glyphosate from foliar tissues into the root system and UABs to locally inhibit EPSPS, and/or 2) translocation and compartmentalization of foliar shikimate into the root system or UABs. However, there is more support for the first option based on previous reports indicating that glyphosate or its metabolites are translocated into the roots and UABs of leafy spurge [12], similar to that reported in other weedy species $[15,50]$.

Although crown buds of foliar glyphosate-treated leafy spurge initially had increased shikimate abundance prior to decapitation, in subsequent generations of aerial shoots (six weeks post-decapitation) shikimate abundance decreased and was similar to that observed in untreated 
Table 6 Changes in transcript abundance of ABC Transporters and Glutathione Transferases (GSTs)

\begin{tabular}{|c|c|c|c|c|c|}
\hline Category & Gene ID Abv. & Gene ID & $\log 2$ FC & TAIR ID & Component number \\
\hline$A B C$ & ABCG2 & ATP-BINDING CASSETTE G2 & 1.70 & AT2G37360.1 & comp66100_c0 \\
\hline \multirow[t]{13}{*}{ transporters } & ABCG5 & ATP-BINDING CASSETTE G5 & 1.53 & AT2G13610.1 & comp76645_c0 \\
\hline & ABCG6 & ATP-BINDING CASSETTE G6 & -4.14 & AT5G13580.1 & comp52290_c0 \\
\hline & ABCG6 & ATP-BINDING CASSETTE G6 & 1.91 & AT5G13580.1 & comp60677_c0 \\
\hline & ABCG8 & ATP-BINDING CASSETTE G8 & 1.85 & AT5G52860.1 & comp69526_c0 \\
\hline & ABCG14 & ATP-BINDING CASSETTE G14 & 1.71 & AT1G31770.1 & comp75586_c0 \\
\hline & ABCG25 & ATP-BINDING CASSETTE G25 & 1.12 & AT1G71960.1 & comp78609_c0 \\
\hline & ABCG40 & ATP-BINDING CASSETTE G40 & -2.65 & AT1G15520.1 & comp29716_c0 \\
\hline & ABCG40 & ATP-BINDING CASSETTE G40 & 2.67 & AT1G15520.1 & comp60991_c0 \\
\hline & ABCG40 & ATP-BINDING CASSETTE G40 & -3.62 & AT1G15520.1 & comp66678_c0 \\
\hline & ABCG40 & ATP-BINDING CASSETTE G40 & -4.54 & AT1G15520.1 & comp66678_c1 \\
\hline & ABCG40 & ATP-BINDING CASSETTE G40 & -4.01 & AT1G15520.1 & comp66678_c2 \\
\hline & ABCG40 & ATP-BINDING CASSETTE G40 & -4.39 & AT1G15520.1 & comp66678_c3 \\
\hline & ABCG40 & ATP-BINDING CASSETTE G40 & -2.33 & AT1G15520.1 & comp77719_c0 \\
\hline \multirow[t]{9}{*}{ GSTs } & GST30 & GLUTATHIONE S-TRANSFERASE 30 & 0.81 & AT1G10370.1 & comp68719_c0 \\
\hline & GSTF11 & GLUTATHIONE S-TRANSFERASE F11 & 4.22 & AT3G03190.1 & comp70895_c0 \\
\hline & GSTL2 & GLUTATHIONE TRANSFERASE LAMBDA 2 & 0.59 & AT3G55040.1 & comp73284_c0 \\
\hline & GSTU6 & GLUTATHIONE S-TRANSFERASE TAU 6 & -0.49 & AT2G29440.1 & comp79342_c1 \\
\hline & GSTU25 & GLUTATHIONE S-TRANSFERASE TAU 25 & 1.48 & AT1G17180.1 & comp62755_c0 \\
\hline & GSTU25 & GLUTATHIONE S-TRANSFERASE TAU 25 & -0.72 & AT1G17180.1 & comp78043_c0 \\
\hline & GSTU25 & GLUTATHIONE S-TRANSFERASE TAU 25 & 2.16 & AT1G17180.1 & comp84357_c0 \\
\hline & GSTT1 & GLUTATHIONE S-TRANSFERASE THETA 1 & -0.44 & AT5G41210.1 & comp69253_c0 \\
\hline & GSTZ1 & GLUTATHIONE S-TRANSFERASE ZETA 1 & 1.03 & AT2G02390.1 & comp77147_c0 \\
\hline
\end{tabular}

Transcript changes after foliar glyphosate treatment $\left(2.24 \mathrm{~kg} \mathrm{ha}^{-1}\right)$ compared to controls in aerial tissues derived from crown buds of leafy spurge. The Arabidopsis Information Resource was used to annotate homologs of leafy spurge transcripts (TAIR ID), to obtain gene IDs and abbreviations (Abv.); values represent $\log 2$ fold changes (FC)

controls (Fig. 2). These results suggest that duration of time after growth induction either allowed for dissipation of shikimate originally observed in crown buds, or EPSPS is no longer inhibited. However, the reduction in shikimate levels did not reverse the glyphosate-induced phenotype (Fig. 1, and Additional file 1). Studies in Arabidopsis revealed that shikimate can be consumed as a secondary metabolite as an ester [51]. Further, silencing of a gene (HYDROXYCINNAMOYL-COA SHIKIMATE/QUINATE HYDROXYCINNAMOYLTRANSFERASE) downstream of the chorismate pathway (i.e., phenylpropanoid metabolism) that involves shikimate recycling causes stunting [51] similar to that observed in this study, which appears to inhibit polar auxin transport [52]. The results of this study (Fig. 2) are consistent with abundance of shikimate initially increasing after glyphosate-treatment in other plant systems and then decreasing over time [48, 53-55]. For example, abundance of shikimate generally peaks between 4 or 7 days after glyphosate-treatment in crops such as corn, soybean (Glycine max), sunflower (Helianthus annuus), and wheat $[48,53]$, and in several weedy species [54].
Even though glyphosate is known to be metabolized in plants and presence of glyphosate oxidoreductase-like enzymes (involved in the degradation pathway of glyphosate in soil) have been speculated, to date no corresponding enzymes or genes have been identified [55, 56]. Therefore, we are not able to determine the extent of glyphosate metabolism based on transcript abundance in leafy spurge. Previous studies [50] have shown that ${ }^{14} \mathrm{C}$-glyphosate levels remain similar in leaves and roots of field bindweed, Canada thistle (Cirsium arvense), and tall morning glory (Ipomoea purpurea) 3-4 weeks post-application, with only a limited accumulation of the main glyphosate metabolite aminomethylphosphonic acid (AMPA). However, in glyphosate-resistant soybean, the highest levels of glyphosate and AMPA were found in treated leaves within 1 day after glyphosate treatment and gradually decreased within 3 weeks [56]. Further, while exogenous application of AMPA did not affect shikimate levels it had phytotoxic effects and induced some injuries (e.g., reduced chlorophyll content, shoot fresh weight) in glyphosate resistant and non-resistant soybean [56]; but, stunted or bushy phenotypes were not reported after AMPA application. 
Because growth-induction of leafy spurge crown buds results in decreased abundance of starch and sucrose and increased abundance of fructose [57], it appears that storage reserves in the root system are remobilized into free sugars to provide an energy source for new vegetative shoot growth. It is plausible that decapitation-induced growth causes a similar process to occur where root sequestered glyphosate or its metabolites, if any, are remobilized into UABs. Remobilization of these substances could cause subsequent-generations of vegetative growth to continually be exposed to residual toxicity and impact SAM maintenance and axillary bud outgrowth. Glyphosate's effects on meristematic tissues over extended periods in white birch (Betula papyrifera) has also been speculated to involve sugar flow into the root system in the fall and a reverse flow of sugar to developing leaves in the spring [58]. This hypothesis is consistent with glyphosate being mobilized to sink tissues such as growing meristems via the phloem [59]. Alternatively, it is possible that glyphosate has an irreversible effect on the main SAM of UABs prior to decapitation-induced growth. The effects of glyphosate on a select set of molecular processes in crown buds of foliar glyphosate-treated plants [28], and increased abundance of shikimate in crown buds 7 days posttreatment (Fig. 2), would support this hypothesis.

\section{Auxin, cytokinin, strigolactone cross-talk and shoot branching}

Shoot branching is known to involve the key hormones auxin, cytokinin, and strigolactones [31, 60]. The increased abundance of transcripts homologous to Arabidopsis genes involved in the IPA biosynthetic pathway leading to auxin (Fig. 3), along with the increased levels of auxin in subsequent generations of aerial tissues from glyphosate-treated plants suggest that tryptophandependent auxin biosynthesis is not inhibited at this stage of development. These results also fit well with the abundance of shikimate observed in the same aerial tissues (Fig. 2). Because increased abundance of shikimate is a marker for inhibition of EPSPS, the increased abundance of auxin and similar levels of shikimate in both glyphosate treated and control plants suggest that EPSPS is not inhibited in subsequent generations of aerial shoots (Fig. 2). These results may suggest either lack of glyphosate or inhibition of its transport into plastids in these shoots, therefore not affecting the chorismate pathway or its downstream auxin biosynthesis pathway. However, we cannot rule out the possibility that the increase in auxin could also be due to an increase in the number of growing meristems.

In this study, the bushy phenotypes derived from crown buds of foliar glyphosate-treated plants do not appear to have a dominant/leading apical meristem to suppress outgrowth of axillary buds (Fig. 1), suggesting that apical dominance is lacking in the system and/or the polar auxin transport stream is affected. Previous studies have shown that exogenous application of auxin represses stem elongation of shoots derived from crown buds of leafy spurge $[57,61]$, which may have some bearing on the reduced main stem elongation and increased branching in response to glyphosate (Fig. 1). Indeed, auxin has been proposed to regulate shoot branching through at least two processes [31, 32]. First, the canalization theory involves the effects of apical dominance on abundance and transport of auxin in stems, which is proposed to inhibit auxin transport from axillary buds to repress axillary bud outgrowth. The second proposed mechanism involves auxin's impact on acropetal movement of cytokinins and strigolactone into the buds to regulate bud outgrowth [62-66]. However, whereas cytokinins induce bud outgrowth, strigolactone signaling can affect PIN1 polarization in the plasma membrane to inhibit auxin transport [32].

PINs encode auxin efflux carriers that mediate tissuespecific, cell-to-cell polar auxin transport [67] critical for developmental patterning and differential growth responses [68]. Strigolactone biosynthesis or signaling mutants also have increased axillary bud outgrowth, resulting in a bushy and dwarfed phenotype in Arabidopsis [69]; increased branching is also correlated with high levels of PIN1 and auxin in the main stem [70, 71]. However, in this study, the increased transcript abundance for homologs of Arabidopsis MAX1 and MAX3 (Table 1), involved in the strigolactone biosynthesis [69], do not correlate well with the glyphosate-induced branching phenotype. Indeed, the minimal decrease in transcript abundance for a homo$\log$ of $M A X 2$, involved in downstream strigolactone signaling through regulation of PIN1 [32] could account for the increased transcript abundance for PIN1 (Table 1). Assuming that the leafy spurge homologs perform similar functions as their Arabidopsis counterparts, these results suggest that PIN1 could be abundant and affecting auxin transport within the polar auxin transport stream of leafy spurge plants in response to glyphosate, in a manner similar to that previously reported [32].

The increased abundance of bioactive cytokinins (Fig. 4) in the aerial shoots derived from crown buds of foliar glyphosate-treated plants is consistent with axillary bud outgrowth (Fig. 1). Ironically, although bioactive auxin levels were increased, auxin's regulatory role on cytokinin levels and acropetal movement appears to be negated in glyphosate-treated plants. Possible explanations for the disparity of the auxin-cytokinin interaction include the local biosynthesis of cytokinin in aerial shoots, particularly since cytokinins are known to be synthesized in most plant tissues [37]. Indeed, the increased abundance of transcripts (Table 2) homologous to Arabidopsis genes involved in cytokinin biosynthesis (AK2, APT2, APT4, IPT3, $L O G 5)$, and decreased abundance of transcripts involved 
in cytokinin metabolism (CKX3, UGT73C1, UGT74E2) in subsequent generations of aerial shoots in response to glyphosate is consistent with the abundance of cytokinins (Fig. 4). Additionally, cytokinins are also known to impact polar auxin transport through modulation of auxin efflux carrier activity [37]. Interestingly, numerous transcripts homologous to Arabidopsis genes involved in auxin transport had a significant increase in abundance (ABCB19, LAX2, LAX3, PID, PIN1; Table 1). Some of these auxin transporter family members (e.g., PINs, and $A B C$ TRANSPORTERS) also had significant changes in transcript abundance in crown buds of foliar glyphosate-treated plants prior to growth induction by decapitation [28].

Interestingly, sugar signaling, not auxin, has been identified as the main regulator of initial axillary bud outgrowth in pea [60]. Although it is difficult to determine if a similar mechanism involving sugar signaling impacts axillary bud outgrowth in aerial shoots of leafy spurge in response to glyphosate-treatment, Gene Set Enrichment Analyses (GSEA, Additional file 7) did identify both decreased and increased abundance of transcripts associated with carbohydrate metabolism and transport. Although limiting sugars through translocation to the shoot tips of axillary buds is proposed to maintain apical dominance, long-term signaling involving auxin, cytokinin and strigolactone are still thought to play a significant role in branching [60].

\section{Glyphosate induces transcript abundance of large gene families}

Large gene families associated with detoxification processes and resistance to multiple herbicides [72-74] had significant changes in transcript abundance in aerial shoots derived from crown buds of glyphosate-treated plants. For example, members of the P450s (46 of 95 increased), UGTs (13 of 51 increased), GSTs (6 of 10 increased), and $A B C$ TRANSPORTERS (8 of 15 increased) had significant changes in abundance (see Additional file 2). In other plant systems, P450s together with GSTs and UGTs are involved in herbicide biochemical modification through metabolism, whereas ABC TRANSPORTERS are involved in compartmentalizing herbicides and their metabolites; this four-step process is associated with herbicide resistance in some weeds [24, 72, 75-78]. As previously discussed, several homologs of Arabidopsis P450s, UGTs and $A B C$ TRASPORTERs differentially expressed in this study are linked to hormone biosynthesis or signaling (Tables 1-5), and it is possible that other members of these families (see Additional file 2) could be playing some role in reducing the phytotoxic effects of residual glyphosate. Assuming these leafy spurge homologs perform similar functions, significant changes in abundance of these gene families suggest that detoxification processes could play some direct or indirect role in reducing the phytotoxic effects of glyphosate. Alternatively, because glyphosate can rapidly disrupt plastids, chloroplasts, and the endoplasmic reticulum in plants $[79,80]$, and some leafy spurge homologs of P450s (see Additional file 2) are known to be localized in these organelles in other systems [81], it is also possible that residual glyphosate impacts cellular organelles in UABs and could help explain the differential abundance of P450s observed in this study.

\section{Plants treated with glyphosate have reduced levels of bioactive GA}

Even though bioactive GAs were not detectable in any samples (Fig. 5), the results indicate that precursors of bioactive GAs were increased, but the abundance of bioactive GAs may be reduced in subsequent generation of aerial tissues derived from crown buds of glyphosatetreated plants. Further, the decreased abundance of a transcript (GA3OX1) involved in synthesis of bioactive GAs and increased abundance of transcripts (GA2OX2, GA2OX4) involved in catabolism of bioactive GAs (Table 3, and Fig. 5), support the decreased abundance of bioactive GAs observed in glyphosate-treated plants. Overall, these results indicate that downstream GA biosynthesis and signaling are negatively impacted, which could contribute to inhibition of stem elongation of tissues derived from crown buds of foliar glyphosate-treated leafy spurge. This hypothesis is supported by the fact that certain commercial chemicals used to stunt growth (e.g., phosphon D, cycocel, ancymidol and paclobutrazol) do so by inhibiting GA biosynthesis [82].

\section{Conclusions}

Translocation of foliar applied glyphosate and its sequestration into the root system of leafy spurge [12] caused irreversible effects to the main SAM of UABs prior to growth-induction by decapitation of the directly treated aerial tissues. This theory is supported by the increased abundance of shikimate in crown buds post foliar glyphosate-treatment and prior to growth-induction (Fig. 2). After growth-induction by decapitation, this irreversible effect, in turn, causes the main stem of subsequent generations of aerial tissue to lose apical dominance, thus impacting axillary bud outgrowth. Alternatively, the potential remobilization of root-sequestered glyphosate would be consistent with apical meristems of growing shoots acting as sink tissues [15, 83], which is supported by the fact that SNEA (see Additional file 4) highlighted numerous molecular processes associated with SAM maintenance containing transcripts with increased abundance (6 weeks post-decapitation). Collectively, these two hypotheses provide insights into potential mechanisms resulting in glyphosate-induced phenotypes that have reduced main 
stem elongation and increased branching due to axillary bud outgrowth (Fig. 1).

The results of this study are consistent with the known involvement of phytohormone cross-talk to regulate branching. The increased abundance of bioactive auxin and cytokinin (Fig. 2) and PIN1 (Table 1) in subsequent generations of aerial shoots (6 weeks post-decapitation) in response to glyphosate-treatment is consistent with axillary bud outgrowth, assuming auxin is being exported from buds into the polar auxin transport stream [70, 71]. Additionally, the increased abundance of cytokinins in subsequent generations of aerial tissues derived from UABs of glyphosate-treated plants would also be consistent with the increased abundance of transcripts involved in cytokinin biosynthesis (Fig. 4) or associated with cell division processes (Table 2). The increased abundance for homologs of $M A X 1$ and MAX3 suggest that strigolactone biosynthesis may be activated in response to the residual effects of glyphosate. However, in our system, the increased abundance of a PIN1 homolog and branching in response to glyphosate are counterintuitive to increased strigolactone signaling, which can inhibit branching through regulation of auxin transporters such as PIN1 [31, 32, 69].

The differential abundance of transcripts for P450s, known to be localized in plastids, endoplasmic reticulum, and mitochondria, support glyphosate's impact on disruption of these intracellular organelles, as demonstrated in other plant systems $[79,80]$. Further, the differential expression of numerous P450s, GSTs, UGTs, and ABC TRANSPORTERS in subsequent generations of aerial shoots in response to glyphosate (Additional file 2) could suggest the occurrence of detoxification processes through metabolism and/or compartmentalization in these tissues. The fact that homologs of ABC TRANSPORTERS, PINs, and PILS also had differential abundance in crown buds of leafy spurge in response to glyphosate [28] add further support for molecular processes associated with membrane transport and/ or sequestration being impacted by glyphosate-treatment prior to growth-inducing decapitation. Although further research will be needed to determine the exact mechanism leading to these glyphosate-induced phenotypes, this research provides insights for molecular processes associated with stunted growth and increased branching from underground adventitious buds of leafy spurge.

\section{Material and Methods}

Plant material, glyphosate-treatments, and vegetative growth

Leafy spurge plants were propagated from a uniform biotype (1984-ND001) in cone-tainers and maintained in a greenhouse as described by Anderson and Davis [84]. After conducting dose-response experiments using concentration of 0 to $6.72 \mathrm{~kg} \mathrm{ha}^{-1}$ glyphosate as active ingredient, aerial tissues of four-month old greenhouse grown leafy spurge plants were treated with 0 or $2.24 \mathrm{~kg} \mathrm{ha}^{-1}$ glyphosate plus $0.25 \%$ surfactant as described by Doğramac1 et al. [28]. Plants were returned to growth-conducive conditions in a greenhouse after foliar glyphosate-treatment. Each experiment included four biological replicates; aerial tissues of eight plants from each replicate were decapitated 7 days post-application to determine the vegetative growth rate from crown buds as previously described by Foley et al. [85]. After six weeks of vegetative growth from crown buds of foliar glyphosate-treated and control plants, shoot heights were measured and analyzed using the generalized linear mixed model (PROC GLIMMIX) procedure of SAS 9.2. Further, these same cone-tainers were used to determine the longevity of glyphosate's effects on vegetative growth from UABs of glyphosate-treated and control plants; every six weeks aboveground shoots were decapitated for three additional re-growth cycle. However, only the first generation of aerial tissues derived from UABs of glyphosate-treated and control plants were harvested and flash frozen in liquid nitrogen and stored $\min -80{ }^{\circ} \mathrm{C}$ for further experiments i.e., shikimate and phytohormone quantification, and transcript analyses by RNAseq and qRT-PCR. Additionally, aerial tissues of leafy spurge plants, which were directly exposed to the treatments and their crown buds were collected for shikimate quantification 7 days after the treatments.

\section{Quantification of shikimate levels}

Quantification of shikimate in aerial tissues directly exposed to the treatments ( 7 days post-treatment), crown buds of foliar treated plants (7 days post-treatment), and aerial tissues derived from crown buds of foliar treated plants (six weeks after growth-inducing decapitation) were accomplished spectrophotometrically [45, 86]. In brief, 0.5 gram of frozen tissue was extracted in $2 \mathrm{~mL} 0.25 \mathrm{~N} \mathrm{HCl}$ at room temperature. $250 \mu \mathrm{L}$ of this extract was added into one $\mathrm{ml} 0.25 \%(\mathrm{w} / \mathrm{v})$ periodic acid $/ 0.25 \%(\mathrm{w} / \mathrm{v})$ metaperiodate and incubated at $37{ }^{\circ} \mathrm{C}$ for 15 minutes. $1 \mathrm{~mL}$ of $0.6 \mathrm{M} \mathrm{NaOH} / 0.22 \mathrm{M} \mathrm{Na}_{2} \mathrm{SO}_{3}$ was added into the sample and read by a spectrophotometer (Beckman, DU 7400); $510 \mu \mathrm{M}$ shikimate (Sigma) was used as the standard. These assays included four biological and two technical replicates; technical replicates were averaged prior to calculating mean of biological replicates and standard error.

\section{Hormone profiling}

Quantification of phytohormones (ABA and ABA metabolites, auxins, cytokinins, and gibberellins) in the eight aerial tissue samples (2 treatments [controls and $2.24 \mathrm{~kg} \mathrm{ha}^{-1}$ glyphosate] $\times 4$ biological replicates) derived from crown buds of foliar glyphosate-treated plants was conducted at the NRCC-PBI (Saskatoon, SK, Canada) by UPLC-ESI-MS/MS. Deuterated forms of each of the hormones were used as internal standards [87, 88]. Extraction 
and purification of samples and quantification of phytohormones was performed following a procedure described in Chiwocha et al. [89, 90]. Profiling data obtained from four biological replicates were used to calculate the mean and standard error. The list and abbreviations of hormone profiles are provided in Additional file 5.

\section{RNA extraction, cDNA library preparation, and transcript analyses by RNAseq}

Total RNA was purified from the eight aerial tissue samples derived from crown buds of foliar glyphosatetreated plants according to the pine tree RNA extraction protocol [91]. The RNA was treated with amplification grade DNase1 (Invitrogen), quantified by the Qubit $^{\circ} 2.0$ Fluorometer, and quality was confirmed by agarose gel electrophoresis. The RNAseq libraries were prepared with the TruSeq Stranded mRNA LT Sample Preparation Kit (Illumina, Cat. $\left.\mathrm{N}^{\circ} \mathrm{RS}-122-2101\right)$ starting from $1 \mu \mathrm{g}$ of total RNA. The pool of barcoded RNAseq libraries was quantified by qRT-PCR using the Library Quantification kit (Kapa Biosystems, Cat. N ${ }^{\circ}$ KK4824). The size range of the final cDNA libraries was determined on an Agilent bioanalyzer DNA7500 DNA chip (Agilent Technologies). The cDNA libraries were sequenced on one lane for 151 cycles from each end of the cDNA fragments on a HiSeq2500 using a TruSeq SBS sequencing kit version 1 (Illumina). The sequence images were transformed with the Real Time Analysis 1.17.21.2 Illumina software to bcl files, which were demultiplexed to fastq files with CASAVA version 1.8.2. The qualityscores line in fastq files processed with Casava1.8.2 use an ASCII offset of 33 known as Sanger scores.

\section{Transcriptome assembly, annotation and expression analyses}

The Trinity package version trinityrnaseq-r2013-02-25 [92] was utilized to assemble the transcriptome from the RNASeq data. Prior to assembly, adaptor sequences were trimmed and so were any low quality bases $(<30$ phred score) from both ends of the sequence. Sequences of 50 nucleotide and higher were utilized for the Trinity assembly. The assembly was performed as per guidelines in the published protocols [92], and on the Trinity website (http://trinityrnaseq.sourceforge.net/\#running_trinity). The abundance of every gene (component) in each of the eight samples was determined by performing alignment and abundance estimation using the RSEM package [93] (version 1.2.3). Only those genes that had at least one sample with the transcripts per million (TPM) value of $\geq 0.5$ were used as input for the next step. Differential gene expression was performed at the level of genes with the EBSeq package [94] (version 1.0) using the median normalization approach and 10 iterations of the algorithm used by EBSeq.
Genes were called differentially expressed if they had an FDR value of $\leq 0.05$.

Annotation of the assembled transcriptome and predicted proteome was performed with the Trinotate package (version trinotate_r20130826). Transdecoder, a Perl script packaged with Trinity, was used to predict proteins, yielding the most likely longest-ORF peptide candidates file best_candidates.eclipsed_orfs_removed. pep. Analyses were performed as detailed in the Trinotate manual (http://trinotate.sourceforge.net/), with the following noted exceptions. BLASTx of assembled transcripts and BLASTp most likely longest-ORF peptide candidates against UniProt-SwissProt database were run with the options "-evalue 10E-3 -max_target_seqs 5" [95]. For more reliable functional annotation, BLASTx of Trinity.fasta and BLASTp of best_candidates.eclipsed_orfs_removed.pep against Arabidopsis peptides were performed (Athaliana_167_protein.fa from Phytozome v9.0). BLAST output files were parsed to 1 top hit per query with an inhouse Perl script prior to insertion in the Trinotate SQLite database (http://trinotate.sourceforge.net/\#LoadingSQLite). After extraction of the Trinotate annotation report from the database (http://trinotate.sourceforge.net/\#OutputReport), Arabidopsis annotations were added using an inhouse Perl script. The expression data is deposited at Gene Expression Omnibus (http://www.ncbi.nlm.nih.gov/geo/) as GEO dataset query GSE56509.

\section{qRT-PCR analyses}

qRT-PCR was utilized to confirm transcript profiles obtained from RNAseq for selected genes. Sequences from a leafy spurge EST database [96] were used for designing primer pairs using the Primer-Select of Lasergene 8 software program (DNASTAR, Inc., Madison, WI). These primer pairs were used to quantify abundance of selected transcripts (see Additional file 3). Total RNA samples were reverse transcribed into complementary DNA (cDNA) as described in Doğramacı et al. [28]. In brief, $5 \mu \mathrm{g}$ of total RNA was treated with DNase1 amplification grade (Invitrogen), and reverse transcribed using Super Script FirstStrand Synthesis Kit3 (Invitrogen) in a $20 \mu \mathrm{l}$ volume according to the manufacturer's instructions. After cDNA synthesis, each reaction was diluted to $800 \mu$ total volume and stored at $-80{ }^{\circ} \mathrm{C}$. For qRT-PCR reactions, $1 \mu \mathrm{l}$ total cDNA was added to a $10 \mu \mathrm{l}$ PCR reaction mixture containing $5 \mu \mathrm{l}$ of LightCycler ${ }^{\circ} 480$ SYBR Green I Master and $0.5 \mu \mathrm{l}$ of each primer-set. Transcript abundance was measured from three technical and four biological replicates using a LightCycler 480 II (Roche). All transcript values were normalized using the reference genes ARF2, PTB, SAND, and ORE9 identified by Chao et al. [97]. QbasePLUS version 2.4 software (Biogazelle, Ghent, Belgium) was used to normalize expression values. Values from four biological replicates were averaged and data from control 
samples $\left(0 \mathrm{~kg} \mathrm{ha}^{-1}\right)$ were used for baseline expression. Gene abbreviations and descriptions of all putative homologous leafy spurge genes included throughout this report were obtained from an Arabidopsis website (www.arabidopsis.org) and are presented in (see Additional file 2). Pathways in Figs. 2-6 were developed based on the PlantCyc website and/or available literature on hormone biosynthesis/signaling, and more details can be found at http://pmn.plantcyc. org/PLANT/class-tree?object=Pathways.

\section{SNEA and GSEA of transcriptome data}

The entire transcriptome dataset (i.e., transcripts per million values; see Additional file 2) was analyzed using Ariadne Pathway Studio 9.0 Software-Resnet Plant Version 2.1 (Ariadne Genomics Inc., Rockville, MD, USA) to obtain SNEA and GSEA using Mann-Whitney U test algorithm with a 0.05 enrichment $p$ value cutoff. Central hubs of subnetworks were obtained by SNEA (Additional file 4) using the customized advanced parameters to identify the most important biological processes, transcription factors, binding partners, miRNA targets, and protein modification targets for the transcriptome data. GSEA was used to identify predefined sets of genes over-represented between treatments (Additional file 7) based on gene ontology (http://www.geneontology.org/) or AraCyc metabolic pathways (http://pmn.plantcyc.org/).

\section{Additional files}

\section{Additional file 1: Vegetative growth from underground} adventitious buds of glyphosate-treated and control plants. Aerial tissues of control and glyphosate-treated ( 0 or $2.24 \mathrm{~kg} \mathrm{ha}^{-1}$ ) leafy spurge plants were decapitated to induce the first subsequent generation of aerial shoots from crown buds. Then, three additional decapitation and vegetative growth $(\mathrm{VG}-2,-3,-4)$ measurements were repeated every six weeks to monitor longevity of glyphosate's effects on vegetative growth. Vertical bars indicate $95 \%$ confidence limits.

Additional file 2: RNAseq results: List of selected genes; list of 9,283 differentially expressed transcripts with Arabidopsis annotation; list of 12,918 differentially expressed transcripts; raw transcripts per million (TPM) values for each treatment and biological replicate.

Additional file 3: List of primer sequences used for qRT-PCR assays, and correlation coefficient values for qRT-PCR vs. RNAseq.

Additional file 4: Sub-network enrichment analyses.

Additional file 5: List of phytohormone profiles performed.

Additional file 6: Ethylene biosynthesis and signaling pathway.

Additional file 7: Gene set enrichment analyses.

\section{Competing interest}

The authors declare that they have no competing interests.

\section{Author contributions}

$M D, J V A, M E F$ and MEM conceived and designed the experiments. MD and AGH performed the experiments. MD, RSK, CJF, KMK and DPH analyzed the data. MD and JVA wrote the paper. All authors revised and approved the final manuscript.

\section{Acknowledgements}

The authors thank Brant B. Bigger, Leonard W. Cook and Cheryl A. Huckle for their technical assistance, and Dr. Suzanne Abrams and Dr. L. Irina Zaharia for collaboration on phytohormone profiling. We also thank Dr. Dale L. Shaner for providing the protocol for quantifying shikimate abundance. Mention of trade names or commercial products in this publication is solely for the purpose of providing specific information and does not imply recommendation or endorsement by the U.S. Department of Agriculture. USDA is an equal opportunity provider and employer.

\section{Author details}

${ }^{1}$ United States Department of Agriculture, Agricultural Research Service, Sunflower and Plant Biology Research, Fargo, ND 58102, USA. ' University of Illinois, W.M. Keck Center for Comparative and Functional Genomics, Urbana, IL 61801, USA. ³ Department of Crop Sciences, 2608 Institute for Genomic Biology, and Roy J. Carver Biotechnology Center, University of Illinois, Urbana, IL 61801, USA.

Received: 6 June 2014 Accepted: 11 May 2015

Published online: 19 May 2015

\section{References}

1. Duke SO, Powels SB. Glyphosate: a once-in-a-century herbicide. Pest Manag Sci. 2008;64:319-25.

2. Duke SO, Powles SB. Glyphosate-resistant crops and weeds: Now and in the future. AgBioforum. 2009;12:346-57.

3. Bryson CT, Wills GD. Susceptibility of bermudagrass (Cynodon dactylon) biotypes to several herbicides. Weed Sci. 1985;33:848-52.

4. Westwood JH, Tominaga T, Weller SC. Characterization and breakdown of self-incompatibility in field bindweed (Convolvulus arvensis L.). J Hered. 1997:88:459-65.

5. Gottrup O, O'Sullivan PA, Schraa RJ, VandenBorn WH. Uptake, translocation, metabolism and selectivity of glyphosate in Canada thistle and leafy spurge. Weed Res. 1976;16:197-201.

6. Wyrill III JB, Burnside OC. Absorption, translocation, and metabolism of 2,4-D and glyphosate in common milkweed and hemp dogbane. Weed Sci. 1976;24:557-66.

7. Cramer GL, Burnside OC. Control of common milkweed (Asclepias syriaca). Weed Sci. 1981;29:636-40.

8. Lym RG. Leafy spurge (Euphorbia esula) control with glyphosate plus 2,4-D. J Range Manage. 2000;53:68-72.

9. Anderson JV, Horvath DP, Chao WS, Foley ME: Bud dormancy in perennial plants: A mechanism for survival. In: Lubzens E, Cerda J and Clark M, editors, Dormancy and Resistance in Harsh Environments. Topics in Current Genetics vol 21. Springer-Verlag Berlin Heidelberg; 2010. p. 69-90.

10. Coupland D, Caseley JC. Reduction of silica and increase in tillering induced in Agropyron repens by glyphosate. J Exp Bot. 1975;26:138-44.

11. Waldecker MA, Wyse DL. Chemical and physical effects of the accumulation of glyphosate in common milkweed (Asclepias syriaca) root buds. Weed Sci. 1985:33:605-11.

12. Maxwell BD, Foley ME, Fay PK. The influence of glyphosate on bud dormancy in leafy spurge (Euphorbia esula). Weed Sci. 1987;35:6-10.

13. Baur JR. Reduction of glyphosate induced tillering in sorghum (Sorghum bicolor) by several chemicals. Weed Sci. 1979;27:69-73.

14. Lee $\Pi$. Release of lateral buds from apical dominance by glyphosate in soybean and pea seedlings. J Plant Growth Regul. 1984;3:227-35.

15. Shaner DL. Role of translocation as a mechanism of resistance to glyphosate. Weed Sci. 2009;57:118-23.

16. Della-Cioppa G, Bauer SC, Klein BK, Shah DM, Fraley RT, Kishore GM. Translocation of the precursor of 5-enolpyruvulshikimate-3-phosphate synthase into chloroplasts of higher plants in vitro. Proc Natl Acad Sci U S A. 1986;83:6873-7.

17. Amrhein N, Deus B, Gehrke P, Steinrucken HC. The site of the inhibition of the shikimate pathway by glyphosate. II. Interference of glyphosate with chorismate formation in vivo and in vitro. Plant Physiol. 1980;66:830-4.

18. Steinrucken HC, Amrhein N. The herbicide glyphosate is a potent inhibitor of 5-enolpyruvylshikimic acid-3-phospahte synthase. Biochem Biophys Res Comm. 1980;94:1207-12.

19. Boocock MR, Coggins JR. Kinetics of 5-enolpyruvylshikimate-3-phosphate synthase inhibition by glyphosate. FEBS Lett. 1983;154:127-33. 
20. Gruys KJ, Walker MC, Sikorski JA. Substrate synergism and the steady-state kinetic reaction mechanism for EPSP synthase from Escherichia coli. Biochemistry. 1992;31:5534-44.

21. Franz JE, Mao MK, Sikorski JA. Glyphosate: a unique global herbicide. Am Chem Soc Monogr. 1997;189:521-615.

22. Herrmann KM, Weaver LM. The shikimate pathway. Annu Rev Plant Physiol Plant Mol Biol. 1999;50:473-503.

23. Zhu J, Patzoldt WL, Shealy RT, Vodkin LO, Clough SJ, Tranel PJ. Transcriptome response to glyphosate in sensitive and resistant soybean. J Agric Food Chem. 2008;56:6355-63.

24. Peng Y, Abercrombie LL, Yuan JS, Riggins CW, Sammons RD, Tranel PJ, et al. Characterization of the horseweed (Conyza canadensis) transcriptome using GS-FLX 454 pyrosequencing and its application for expression analysis of candidate non-target herbicide resistance genes. Pest Manag Sci. 2010;66:1053-62.

25. Yuan JS, Abercrombie LLG, Cao Y, Halfhill MD, Zhou X, Peng Y, et al. Functional genomics analysis of horseweed (Conyza canadensis) with special reference to the evolution of non target-site glyphosate resistance. Weed Sci. 2010;58:109-17.

26. Cebeci O, Budak H. Global expression patterns of three Festuca species exposed to different doses of glyphosate using the Affymetrix GeneChip wheat genome array. Comp Funct Genomics. 2009;2009:505701.

27. Unver T, Bakar M, Shearman RC, Budak H. Genome-wide profiling and analysis of Festuca arundinacea miRNAs and transcriptomes in response to foliar glyphosate application. Mol Genet Genom. 2010;283:397-413.

28. Doğramacı M, Anderson JV, Chao WS, Foley ME. Foliar application of glyphosate affects molecular mechanisms in underground adventitious buds of leafy spurge (Euphorbia esula) and alters their vegetative growth patterns. Weed Sci. 2014;62:217-29.

29. Lang GA. Dormancy: A new universal terminology. Hort Sci. 1987;22:817-20.

30. Horvath DP. Role of mature leaves in inhibition of root bud growth in Euphorbia esula L. Weed Sci. 1999:47:544-50.

31. Vanstraelen M, Benková E. Hormonal interactions in the regulation of plant development. Annu Rev Cell Dev Biol. 2012;28:463-87.

32. Shinohara N, Taylor C, Leyser O. Strigolactone can promote or inhibit shoot branching by triggering rapid depletion of the auxin efflux protein PIN1 from the plasma membrane. PLoS Biol. 2013;11, e1001474.

33. Mashiguchi K, Tanaka K, Sakai T, Sugawara S, Kawaide H, Natsume M, et al. The main auxin biosynthesis pathway in Arabidopsis. Proc Natl Acad Sci U S A. 2011;108:18512-7.

34. Mano Y, Nemoto K. The pathway of auxin biosynthesis in plants. J Exp Bot. 2012;63:2853-72

35. Zhao Y, Hull AK, Gupta NR, Goss KA, Alonso J, Ecker JR, et al. Trp-dependent auxin biosynthesis in Arabidopsis: involvement of cytochrome P450s CYP79B2 and CYP79B3. Genes Develop. 2002;16:3100-12.

36. Werner T, Motyka V, Strnad M, Schmulling T. Regulation of plant growth by cytokinin. Proc Natl Acad Sci U S A. 2001;98:10487-92.

37. Jones B, Gunneras SA, Petersson SV, Tarkowski P, Graham N, May S, et al. Cytokinin regulation of auxin synthesis in Arabidopsis involves a homeostatic feedback loop regulated via auxin and cytokinin signal transduction. Plant Cell. 2010;22:2956-69.

38. Hirsch S, Oldroyd GED. GRAS-domain transcription factors that regulate plant development. Plant Signal Behav. 2009:4:698-700.

39. Yamashino T, Kitayama M, Mizuno T. Transcription of ST2A encoding a sulfotransferase family protein that is involved in jasmonic acid metabolism is controlled according to the circadian clock- and PIF4/PIF5-mediated external coincidence mechanism in Arabidopsis thaliana. Biosci Biotechnol Biochem. 2013;77:2454-60

40. Doğramacı M, Foley ME, Chao WS, Christoffers MJ, Anderson JV. Induction of endodormancy in crown buds of leafy spurge (Euphorbia esula L.) implicates a role for ethylene and cross-talk between photoperiod and temperature. Plant Mol Biol. 2013;81:577-93.

41. Baur JR, Bovey RW, Veech JA. Growth responses in sorghum and wheat induced by glyphosate. Weed Sci. 1977;25:238-40.

42. Roider CA, Griffin JL, Harrison SA, Jones CA. Wheat response to simulated glyphosate drift. Weed Technol. 2007;21:1010-5.

43. Kutman BY, Kutman UB, Cakmak I. Foliar nickel application alleviates detrimental effects of glyphosate drift on yield and seed quality of wheat. J Agr Food Chem. 2013;61:8364-72.

44. Wang CY. Effect of glyphosate on aromatic amino acid metabolism in purple nutsedge (Cyperus rotundus). Weed Technol. 2001;15:628-35.
45. Shaner DL, Nadler-Hassar T, Henry WB, Koger CH. A rapid in vivo shikimate accumulation assay with excised leaf discs. Weed Sci. 2005;53:769-74.

46. Gaines TA, Zhang W, Wang D, Bukun B, Chisholm ST, Shaner DL, et al. Gene amplification confers glyphosate resistance in Amaranthus palmeri. Proc Natl Acad Sci U S A. 2010;107:1029-34

47. Nol N, Tsikou D, Eid M, Livieratos IC, Giannopolitis CN. Shikimate leaf disc assay for early detection of glyphosate resistance in Conyza canadensis and relative transcript levels of EPSPS and ABC transporter genes. Weed Res. 2012;52:233-41.

48. Henry WB, Shaner DL, West MS. Shikimate accumulation in sunflower, wheat, and proso millet after glyphosate application. Weed Sci. 2007:55:1-5.

49. Anderson JV, Gesch RW, Jia Y, Chao WS, Horvath DP. Seasonal shifts in dormancy status, carbohydrate metabolism, and related gene expression in crown buds of leafy spurge. Plant Cell Environ. 2005;28:1567-78.

50. Sandberg CL, Meggit WF, Penner D. Absorption, translocation and metabolism of ${ }^{14} \mathrm{C}$ labeled glyphosate in several weed species. Weed Res. 1980:20:195-200.

51. Hoffmann L, Besseau S, Geoffroy P, Ritzenthaler C, Meyer D, Lapierre C, et al. Silencing of hydroxycinnamoyl-coenzyme a shikimate/quinate hydroxycinna moyltransferase affects phenylpropanoid biosynthesis. Plant Cell. 2004;16:1446-65.

52. Li X, Bonawitz ND, Weng JK, Chapple C. The growth reduction associated with repressed lignin biosynthesis in Arabidopsis thaliana is independent of flavonoids. Plant Cell. 2010:22:1620-32.

53. Henry WB. Koger $\mathrm{CH}$. Accumulation of shikimate in corn and soybean exposed to various rates of glyphosate. Crop Manage: Shaner DL; 2005.

54. Mueller TC, Tellis A, Beeler JE, Sharma SD, Singh M. Shikimate accumulation in nine weedy species following glyphosate application. Weed Res. 2008:48:455-60

55. Duke SO. Glyphosate degradation in glyphosate-resistant and -susceptible crops and weeds. J Agr Food Chem. 2010;59:5835-41.

56. Reddy KN, Rimando AM, Duke SO. Aminomethylphosphonic acid, a metabolite of glyphosate, causes injury in glyphosate-treated, glyphosate-resistant soybean J Agr Food Chem. 2004;52:5139-43

57. Chao WS, Serpe MD, Anderson JA, Gesch RW, Horvath DP. Sugars, hormones, and environment affects the dormancy status in underground adventitious buds of leafy spurge (Euphorbia esula). Weed Sci. 2006:54:59-68.

58. Stasiak MA, Hofstra G, Fletcher RA. Physiological changes induced in birch seedlings by sublethal applications of glyphosate. Can J for Res. 1992;22:812-7.

59. Geiger DR, Bestman HD. Self-limitation of herbicide mobility by phytotoxic action. Weed Sci. 1990;38:324-9.

60. Mason MG, Ross JJ, Babst BA, Wienclaw BN, Beveridge CA. Sugar demand, not auxin, is the initial regulator of apical dominance. Proc Natl Acad Sci U S A. 2014;111:6092-7.

61. Horvath DP. The role of specific plant organs and polar auxin transport in correlative inhibition of leafy spurge (Euphorbia esula L.) root buds. Can J Bot. 1998:76:1227-31.

62. Stirnberg P, Furner IJ, Ottoline Leyser HM. MAX2 participates in an SCF complex which acts locally at the node to suppress shoot branching. Plant J. 2007;50:80-94.

63. Gomez-Roldan V, Fermas S, Brewer PB, Puech-Pages V, Dun EA, Pillot JP, et al. Strigolactone inhibition of shoot branching. Nature. 2008;455:189-94.

64. Umehara M, Hanada A, Yoshida S, Akiyama K, Arite T, Takeda-Kamiya N, et al. Inhibition of shoot branching by new terpenoid plant hormones. Nature. 2008;455:195-200.

65. Hayward A, Stirnberg P, Beveridge C, Leyser O. Interactions between auxin and strigolactone in shoot branching control. Plant Physiol. 2009;151:400-12.

66. Hamiaux C, Drummond RSM, Janssen BJ, Ledger SE, Cooney JM, Newcomb $\mathrm{RD}$, et al. DAD2 is an alpha_beta hydrolase likely to be involved in the perception of the plant branching hormone, strigolactone. Curr Biol. 2012;22:2032-6.

67. Peer WA. From perception to attenuation: auxin signalling and responses. Curr Opin Plant Biol. 2013;16:561-8.

68. Blilou I, Xu J, Wildwater M, Willemsen V, Paponov I, Friml J, et al. The PIN auxin efflux facilitator network controls growth and patterning in Arabidopsis roots. Nature. 2005:433:39-44.

69. Domagalska MA, Leyser O. Signal integration in the control of shoot branching. Nat Rev Mol Cell Biol. 2011;12:211-21.

70. Bennett T, Sieberer T, Willett B, Booker J, Luschnig C, Leyser O. The Arabidopsis MAX pathway controls shoot branching by regulating auxin transport. Curr Biol. 2006;16:553-63. 
71. Prusinkiewicz P, Crawford S, Smith RS, Ljung K, Bennett T, Ongaro V, et al. Control of bud activation by an auxin transport switch. Proc Natl Acad Sci U S A. 2009;106:17431-6.

72. Cummins I, Wortley DJ, Sabbadin F, He Z, Coxon CR, Straker HE, et al. Key role for a glutathione transferase in multiple-herbicide resistance in grass weeds. Proc Natl Acad Sci U S A. 2013;110:5812-7.

73. Cummins I, Moss S, Cole DJ, Edwards R. Glutathione trasferases in herbicideresistant and herbicide-susceptible black-grass (Alopercurus myosuroides). Pestic Sci. 1997:51:244-50.

74. Conte SS, Lloyd AM. Exploring multiple drug and herbicide resistance in plant - spotlight on transporter proteins. Plant Sci. 2011;180:196-203.

75. Werck-Reichhart D, Hehn A, Didierjean L. Cytochromes P450 for engineering herbicide tolerance. Trends Plant Sci. 2000;5:116-23.

76. Brazier M, Cole DJ, Edwards R. O-Glucosyltransferase activities toward phenolic natural products and xenobiotics in wheat and herbicide-resistant and herbicide-susceptible black-grass (Alopecurus myosuroides). Phytochemistry. 2002;59:149-56.

77. Yanhui C, Xiaoyuan Y, Kun H, Meihua L, Jigang L, Zhaofeng G, et al. The MYB transcription factor superfamily of Arabidopsis: expression analysis and phylogenetic comparison with the rice MYB family. Plant Mol Biol. 2007;60:107-24.

78. Busi R, Vila-Aiub MM, Powles SB. Genetic control of cytochrome P450 metabolism-based herbicide resistance mechanism in Lolium rigidum. Heredity. 2011;106:817-24.

79. Campbell WF, Evans JO, Reed SC. Effect of glyphosate on chloroplast ultrastructure of quackgrass mesophyll cells. Weed Sci. 1976;24:22-5.

80. Mollenhauer C, Smart CC, Amrhein N. Glyphosate toxicity in the shoot apical region of the tomato plant I. Plastid swelling is the initial ultrastructural feature following in vivo inhibition of 5-enolpyruvylshikimic acid 3-phosphate synthase. Pestic Biochem and Phys. 1987;29:55-65.

81. Neve EPA, Ingelman-Sundberg M. Cytochrome P450 proteins: retention and distribution from the endoplasmic reticulum. Curr Opin Drug Discov Devel. 2010;13:78-85.

82. Sponsel VM, Hedden P. Gibberellin biosynthesis and inactivation. In: Davies PJ, editor. Plant Hormones: Biosynthesis, Signal Transduction, Action! The Netherlands: Kluwer Academic Publishers; 2004. p. 63-94.

83. Ge X, d'Avignon DA, Ackerman JJH, Douglas Sammons R. Rapid vacuolar sequestration: The horseweed glyphosate resistance mechanism. Pest Manag Sci. 2010;66:345-8.

84. Anderson JV, Davis DG. Abiotic stress alters transcript profiles and activity of glutathione S-transferase, glutathione peroxidase, and glutathione reductase in Euphorbia esula. Physiol Plantarum. 2004;120:421-33.

85. Foley ME, Anderson JV, Horvath DP. The effects of temperature, photoperiod, and vernalization on regrowth and flowering competence in Euphorbia esula (Euphorbiaceae) crown buds. Botany. 2009;87:986-92.

86. Cromartie $\mathrm{TH}$, Polge ND. An improved assay for shikimic acid and its use as a monitor for the activity of sufosate. Proc Weed Sci Soc Am. 2000;40:291.

87. Abrams SR, Nelson K, Ambrose SJ. Deuterated abscisic acid analogs for mass spectrometry and metabolism studies. J Labelled Compd Radiopharm. 2003;46:273-83.

88. Zaharia LI, Galka MM, Ambrose SJ, Abrams SR. Preparation of deuterated abscisic acid metabolites for use in mass spectrometry and feeding studies. J Labelled Compd Radiopharm. 2005;48:435-45.

89. Chiwocha SDS, Abrams SR, Ambrose SJ, Cutler AJ, Loewen M, Ross ARS, et al. A method for profiling classes of plant hormones and their metabolites using liquid chromatography-electrospray ionization tandem mass spectrometry: an analysis of hormone regulation of thermodormancy of lettuce (Lactuca sativa L.) seeds. Plant J. 2003;35:405-17.

90. Chiwocha SDS, Cutler AJ, Abrams SR, Ambrose SJ, Yang J, Ross ARS, et al. The etr1-2 mutation in Arabidopsis thaliana affects the abscisic acid, auxin, cytokinin and gibberellin metabolic pathways during maintenance of seed dormancy, moist-chilling and germination. Plant J. 2005;42:35-48.

91. Chang S, Puryear J, Cairney J. A simple and efficient method for isolating RNA from pine trees. Plant Mol Biol Rep. 1993;11:113-6.

92. Haas BJ, Papanicolaou A, Yassour M, Grabherr M, Blood PD, Bowden J, et al. De novo transcript sequence reconstruction from RNA-seq using the Trinity platform for reference generation and analysis. Nature Prot. 2013;8:1494-512.

93. Li B, Dewey CN. RSEM: accurate transcript quantification from RNA-seq data with or without a reference genome. MC Bioinformatics. 2011;12:323.
94. Leng N, Dawson JA, Thompson JA, Ruotti V, Rissman Al, Smits BMG, et al. EBSeq: An empirical Bayes hierarchical model for inference in RNA-seq experiments. Bioinformatics. 2013;29:1035-43.

95. Altschul SF, Gish W, Miller W, Myers EW, Lipman DJ. Basic local alignment search tool. J Mol Biol. 1990;215:403-10.

96. Anderson JV, Horvath DP, Chao WS, Foley ME, Hernandez AG, Thimmapuram J, et al. Characterization of an EST database for the perennial weed leafy spurge: An important resource for weed biology research. Weed Sci. 2007;55:193-203.

97. Chao WS, Doğramacı M, Foley ME, Horvath DP, Anderson JV. Selection and validation of endogenous reference genes for qRT-PCR analysis in leafy spurge (Euphorbia esula). PLoS One. 2012;7, e42839.

\section{Submit your next manuscript to BioMed Central and take full advantage of:}

- Convenient online submission

- Thorough peer review

- No space constraints or color figure charges

- Immediate publication on acceptance

- Inclusion in PubMed, CAS, Scopus and Google Scholar

- Research which is freely available for redistribution 